\title{
Crack Detection in Shaft Using Lateral and Torsional Vibration Measurements and Analyses
}

\author{
A. Tlaisi ${ }^{1}$, A. Akinturk ${ }^{1}$, A. S. J. Swamidas ${ }^{1} \&$ M. R. Haddara ${ }^{1}$ \\ ${ }^{1}$ Faculty of Engineering and Applied Science, Memorial University of Newfoundland, St. John's, Canada \\ Correspondence: A. Tlaisi, Faculty of Engineering and Applied Science, Memorial University of Newfoundland, \\ St. John’s, Canada. E-mail: atlaisi@mun.ca
}

Received: July 6, 2012 Accepted: July 25, 2012 Online Published: August 24, 2012

doi:10.5539/mer.v2n2p52 URL: http://dx.doi.org/10.5539/mer.v2n2p52

\begin{abstract}
Cracking of cylindrical shafts is an important area for research, since the changes observed in their vibration characteristics even during large-sized cracking are much smaller than those observed for rectangular beams; hence early identification of crack existence becomes essential to prevent sudden failures in rotating shafts. In this paper experimental and numerical investigations are carried out to identify the presence of a crack in a cylindrical overhanging shaft with a propeller at the free end. In the experimental study, cracks of different depths are located at the (un-cracked) maximum bending moment position. Shaft response parameters for lateral (using an accelerometer) and torsional vibrations (using shear strain gages fixed at three different locations) are obtained using the modal analysis software, LMS Test $\mathrm{Lab}^{\mathrm{TM}}$. The experimental results are used to validate the numerical results obtained using the three-dimensional isoperimetric elements available in the ANSYS FEM program; the open crack is embedded in the shaft and the mesh generation is suitably modified to incorporate the stress intensity effects present at the crack tip. The results indicate that the use of the rate of change of frequencies, modal amplitudes (of displacements, velocities and accelerations) as a function of crack depth ratio will indicate the presence of crack in the shaft from a crack depth ratio of 0.2. Also the use of the rate of change of torsional frequency will indicate the presence of a crack in the shaft from the initiation of the crack. The approach indicated in this paper will provide a sound and robust procedure for a first level of damage assessment by using vibration techniques.
\end{abstract}

Keywords: experimental investigation, cracked shaft, FEM, modal analysis, ANSYS

\section{Introduction}

The appearance of transverse cracks in overhanging shafts having propellers carries with it a greater risk of sudden collapse. Even though the presence of a crack (or cracks) may not lead to sudden failure, it will considerably affect its dynamic behavior. In the last four decades, many numerical and experimental studies have been carried out to identify the effects of different type of cracks, such as transverse, longitudinal, slant, breathing cracks and notches. In these studies the researchers have used different methods to identify crack presence in structures, viz., (i) Traditional vibration-based methods using modal testing and numerical analysis; (ii) Non-traditional methods based on ultrasonic guided waves, magnetic induction, radiofrequency identification tag, acoustic intensity and acoustic Laser-Doppler vibrometry (Sabnavis, Gordon, Kasarda, \& Quinn, 2004); and (iii) Numerical procedures using FEM in conjunction with modal analysis, wavelet transforms, neural net works, genetic algorithms and fuzzy set theory.

There are two stages of crack development in rotating shafts: crack initiation, and crack propagation. The first is caused by mechanical stress raisers, such as sharp keyways, abrupt cross-sectional changes, heavy shrink fits, dents and grooves, and/or metallurgical factors, such as fretting and forging flaws. The second stage can accelerate the growth rate under certain conditions, viz., (i) operating faults like sustained surging in compressors; (ii) negative sequence current or grounding faults in generators and coupled turbines; (iii) the presence of residual and thermal stresses in the rotor material; and (iv) environmental conditions such as the presence of a corrosive medium. Also, from the physical morphology of a cracked rotor, cracks can be classified based on their geometries as follows: (i) transverse cracks that are perpendicular to the shaft axis; (ii) cracks parallel to the shaft axis known as longitudinal cracks; (iii) slants cracks that are at an angle to the shaft axis; (iv) open and close cracks when the affected part of the material is subjected to tensile stresses and stress 
reversals(breathing cracks); (v) gaping cracks or notches that always remain open; and (vi) surface cracks and subsurface cracks. A number of studies have been carried out on the above crack types (Sabnavis, Gordon, Kasarda, \& Quinn, 2004).

\section{Literature Review}

Hamidi, Piaud and Massoud (1992) developed two mathematical models (using three-dimensional stress intensity factors at the crack region) to determine the bending natural frequencies of a rotor. They used natural frequencies, mode shapes and frequency response functions to identify the crack presence. The analytical methods were compared with the results of experimental measurements. The following conclusions were made: (i) When crack depth was more than $30 \%$ of the shaft radius, the rate of change of natural frequencies was very high; and (ii) The speed of rotating shaft did not affect the values of natural frequencies; this was probably due to the fact that the stiffness of the shafts were not reduced significantly by the rotating speed effects on the shaft.

Schwarz and Richardson (1999) reviewed some of the important articles related to modal testing during the past 30 years. They covered three aspects in this paper, frequency response function measurement techniques, sources of excitation, and methods for extracting modal parameters directly from a set of FRF measurements (frequency, damping, and mode shape). Frequencies, damping and mode shapes were estimated. Also they stated that the mode shapes were obtained from peak values of the imaginary part of the FRF when they used displacement and acceleration FRFs; also mode shape components were obtained from peak values of the real part of the FRF when they used velocity FRF. Zakhezin and Malysheva (2001) used a numerical Finite Element based crack detection technique and modal tests on a single span shaft. They included system damping in their model and calculated the system's eigen-values and eigen-vectors up to a frequency of 1,100 $\mathrm{Hz}$. These values were calculated for a rotor with and without cracks at varying locations and depths. The method was tested and results verified to indicate the good quality of results obtained.

Sekhar and Srinivas (2003) used shell elements with 4 nodes using the CQUAD4 elements available in commercial finite element analysis software NASTRAN and FEMAP to model hollow cracked composite shafts, fabricated using stacking sequences of boron-epoxy, carbon-epoxy and graphite-epoxy materials. The finite element formulation was based on first order shear deformation theory. They created crack on the shaft by using bullion operations. Also spring elements were used to represent the effect of the bearings. They have stated that the stacking sequences such as 90/0/90/0 and 90//90/0/0 produced a higher frequency than other sequences of stacking. They also found that for all the three materials, the eigen-frequencies decreased with increase in crack depth. They also observed that the carbon-epoxy shaft had a higher frequency than the other two materials for the same crack.

Sinouand Lees (2007) analyzed the dynamic response of an on-line rotating shaft to predict the influence of a breathing transverse crack. Also they investigated the development of the orbit of the cracked rotor at half and one-third of the first critical speed. They used Harmonic Balance Method to obtain shaft response parameters by considering the effects of different crack depths and locations. Li et al. (2008) used FE-based simulation (through ANSYS) to model the dynamic characteristics of a faulty multi-span rotor system. This system was connected together by axial membrane coupling, considering each span to be elastic and supporting a rigid rotor at the free end. They examined in detail coupled bending-torsion vibration of a single-span rotor and the whole rotor system; they analyzed four cases for the occurrence of cracks and rubbing faults (crack location was in the middle of the span and the crack depths were $0.0 \mathrm{D}, 0.2 \mathrm{D}, 0.4 \mathrm{D}$, and $0.6 \mathrm{D}$ ). They also examined: (i) Nonlinear dynamic characteristics, (ii) Responses of the rotor system, (iii) The influence of membrane coupling, and (iv) Effect of gearing on the rotor system. They concluded that detailed examination of both the coupling and gear response would help one to properly diagnose the cracks occurring in the rotor-system.

Sudhakar and Sekhar (2010) presented a modified model-based analysis technique and used a modified least squares minimization algorithm to reduce the errors in the identified fault parameters. The idea of this method was to model the fault as an equivalent load that will be generated on the cracked rotor-bearing system; the equivalent loads were calculated using measured vibration responses at all degrees of freedom of the system. The difference between this equivalent load and the theoretical model fault load was minimized by least squares algorithm. Also they used finite element method to validate theoretical results. By this method, it was found easy to identify a crack even when the vibrations were measured with 4 DOF $(8,16,20$, or 24 DOF) systems. They found the method to be very sensitive to the mode shapes and location of the crack.

Downer (2010) used this technique and design of experiments approach to extract the frequencies, mode shapes and damping ratio. He also determined the effect of various structural factors on a measured response and related the modal frequencies to these structural parameters (defect, size and location). He used two types of beam, viz., 
a cantilever beam (clamped-free) and a real prototype beam (Electric transmission tower wooden poles). He used two types of non-destructive test methods to detect hidden internal defects and the strength of the poles. Additionally from experimental work he created regression models of multiple modal frequencies of the beam by using the theory of the design of experiments. The author mentioned that once the regression models were acquired it can be easily used to detect defects in the poles. Finite element analysis also was carried out to validate his experimental work. One of the best results in this research is the capability to predict the maximum stress of specimens by using regression models instead of commercial ultrasonic NDT equipment.

Ganeriwala, Kanakasabai and Richardson (2011) presented experimental results obtained for a wind turbine under the influence of different cracks. Modal testing technique was used. Two single wind turbine blades (4 feet long and made from fiberglass) were used, one was an un-cracked blade and the second was a cracked blade. On the cracked blade there were two cracks, one located along an edge of the blade (5in, 10in, and 20 in deep edge crack) and the other on the surface of the blade(1.3in, 2.6in, and 3.9in deep surface crack). Thirteen accelerometers and an impact hammer were used to obtain modal frequencies, damping, frequency response functions and mode shapes, for both cases; these results were used to predict the presence of the crack. From modal testing they found some modes of the blade to be significantly affected by the presence of crack. The modal parameters were significantly affected by the longer depth of crack. In this study, the following conclusions were made: (i) The modal parameters of modes 3 to 8 showed significant changes due to the presence of edge cracks; (ii) Significant changes in the modal parameters of modes 1 and 2 were observed under the influence of edge or surface cracks; (iii) Lower frequency modes did not indicate the presence of localized blade cracks than higher frequency modes; and (iv) Mode shapes showed significant changes due to the presence edge crack than surface crack.

Elshafey, Marzouk and Haddara (2011) used modal test technique and presented their damage model on the basis of detailed experimental investigations. They used a steel beam fixed at one end and hinged at the other to identify the occurrence and location of structural damage by using the change in the mode shapes. The vibration frequencies and mode shapes as well as FRF function were used. They reported that better results for identifying the structural damage were obtained when they used the results of second mode.

Jian-bin, Hai-feng and Di (2012) investigated the presence of fatigue fracture, in diesel engine crankshafts using dynamic monitoring and detection procedures. They used the metal magnetic memory detection methodology and monitored on-line the changes in engine crankshaft characteristics. They tested a diesel engine generating an acceleration of $295 \mathrm{G}$ and a multi-function electromagnetic detector to detect the presence of stress concentration areas. They used two detecting points on the crack of the crankshaft and used magnetic memory tester to examine the effects of the following parameters: (i) various stress concentration areas were observed and recorded; (ii) different engine speeds were used to observe the changes in magnetic memory signals; and (iii) they measured the changes that occur in between the two detecting points by considering the change in the temperature of crankcase. The authors found no effect in the magnetic memory signal values due to the change of engine speed and temperature, when the temperature was below $500^{\circ} \mathrm{C}$; whereas the change of the inertial loads had clear affects.

Saravanan and Sekhar (2012) used experimental and analytical procedures for monitoring the rotor-bearing system to examine the presence of a transverse breathing crack; they used the concept of operational deflection shape and used kurtosis of vibrating defect's time history. Also the shape and amplitude of kurtosis curve was used to detect crack on the shaft experimentally. Two types of crack on the shaft, a single crack and two cracks were used. In experimental studies, the length and diameter of the shaft were $800 \mathrm{~mm}$ and $16 \mathrm{~mm}$ respectively. The shaft was supported on two ball bearings and the disc (disc mass $=0.656 \mathrm{~kg}$ ) was mounted at the center of this shaft. The breathing crack was located at the middle of the shaft and the shaft was divided into 20 elements to measure the operational deflection shape. They used rotational laser vibrometer to measure the vibration response at different locations on the rotating shaft. The authors found that the changes that occur in the kurtosis were significant when the crack was located close to the bearing locations while it was small when the crack location was closer to the middle. They reported that the use of kurtosis results were useful for identifying the crack during detection and monitoring purposes.

\section{Scope of the Study}

In an earlier paper by the present authors (2011), beam elements available is ANSYS were used in the numerical modeling of the cylindrical shaft; whereas in the present paper 3-D iso-parametric elements (20-noded, 15-noded, 12-noded and 10-noded) were used for modeling the shaft, bearings, supports, propeller, torque loading arm and other accessories. Moreover in the earlier study only support springs were used to represent the 
elastic effects of bearings, supports and other attachments present in the cylindrical shaft system. Hence in the present study a detailed modeling of the bearing connections to the shaft, as well as to the supporting frames, were done to properly include the total effect of the support elasticity. This detailed modeling of the shaft-propeller system using FM procedures has given extensive insights into the behavior of the shaft-propeller system including the overall shaft behavior, the support bending, the local bending of the propeller blades, and the presence of combined modes.

In the present paper three methods were used for the detection of crack in a rotating shaft, viz., (i) An experimental investigation carried out to identify the transverse crack existence in a shaft, having a cantilever overhang - LMS experimental setup was used for measuring and determining the un-cracked and cracked (different crack depths) shaft response parameters; and (ii) Vibration responses of an un-cracked and cracked shaft were obtained numerically using the finite element method and related to the experimental results. 3-D solid elements (types $186 \& 187$ ) available in ANSYS software were used for the numerical analysis; and (iii) Finite element results were used to generate numerical frequency response functions that were used to detect the crack occurrence in the shaft propeller-bearings system and to compare the numerical results with experimental results.

\section{Shaft- propeller-bearing Test Rig and Experimental Setup}

The shaft-propeller system bearing test rig is shown in Figure 1. The shaft was fixed at one end to the test frame support 1 and was continuous over the other frame support 2 to end in a cantilevered end, supporting the propeller. The shaft was supported through ball bearings that were bolted to the two test frame supports. The main objective of this experimental study was to investigate the effect of cracks on the lateral and torsional vibration of the shaft system.

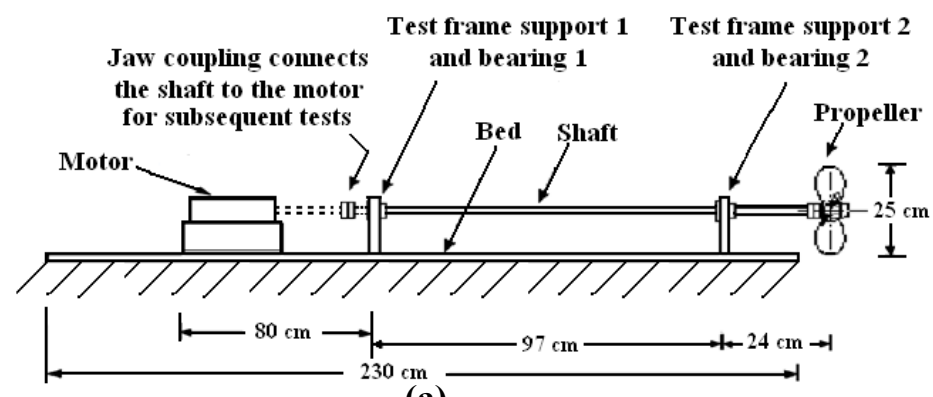

(a)

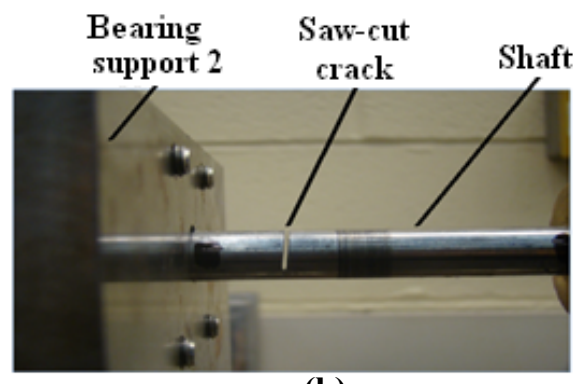

(b)

Figure 1. The saw-cut crack: a) Line diagram of the experimental setup;

b) The right side of bearing support 2

\subsection{Test Rig Description}

The shaft-propeller system consisted of a shaft supported on two bearings, over two fixed steel supports, as shown in Figure 1(a). The length and the diameter of the shaft were, $1220 \mathrm{~mm}$ (to the end of the propeller) and $16 \mathrm{~mm}$, respectively. It was supported on two mounted bearings with greased fittings and deep-grooved ball-bearing inserts of type 5967k81.Twopairs of set screws were used to fix the shaft to the two bearings. Manually-made saw cuts $(0.65 \mathrm{~mm}$ wide) of different depths ratios (from $0 \%$ to $70 \%$ ratio) were made at a distance of $2 \mathrm{~cm}$ to the right of bearing support 2, as shown in Figure 1(a) (in the propeller end). The saw-cut shown in Figure 1(b) had a flat notch end since it was introduced by a hack saw with hardened and serrated cutting blade $0.65 \mathrm{~mm}$ thick. In actual crack situation, the edge will be v-shaped due to cyclic loading during fatigue; this has been simulated in our finite element modeling given later. If it is a flat ended crack, cracking will start from the rectangular corners of the crack, rather than from the center of the crack; this will produce aninclined twin-crack situation during fatigue, rather than the assumed single vertical crack due to the saw cut.

\subsection{Test Instrumentation System}

The test instrumentation system used to measure the two types of vibrations, viz., lateral and torsional modes of the rotating shaft system, is shown in Figure 2(a). For the experimental portion of the study, the Engineering Innovation (LMS Test $\mathrm{Lab}^{\mathrm{TM}}$ ) software package with two measurement channels was used. Modal testscould be done either using a fixed input (with the modal hammer impacting at one location only with many 
accelerometers at different response locations) or a fixed single output (with the accelerometer fixed at one location and hummer impact point moved to different response locations) (Schwarz \& Richardson, 1999).

In this study the second type of time history output from the moving modal hammer accelerometer was used in the study, as shown in Figure 2(c). The number designation of the impact hammer type was 8206-002 and the maximum force (non-destructive) that could be deliveredwas 4448N. Plastic tip (DB-3991-002) material was used for impact hammer modal tests. The second channel recorded the time history output from the accelerometer device shown in Figure 2(c). Figure 2(d) and (e) show the experimental setup to measure torsional vibration of the rotating shaft. In the torsional vibration measurement system three strain gages were fixed at three locations, one placed near the bearing support 1, the second placed at the middle of the supported span, and the last one placed near propeller as shown in Figure 2(d). An aluminum arm, shown in Figure 2(e) was used to apply various magnitudes of impact torque at various locations of shaft. Five data acquisition channels were used in this study, viz., three for torsional strain measuring gages, one for accelerometer channel, and the fifth for impact load with a maximum mass of $22 \mathrm{~kg}$.

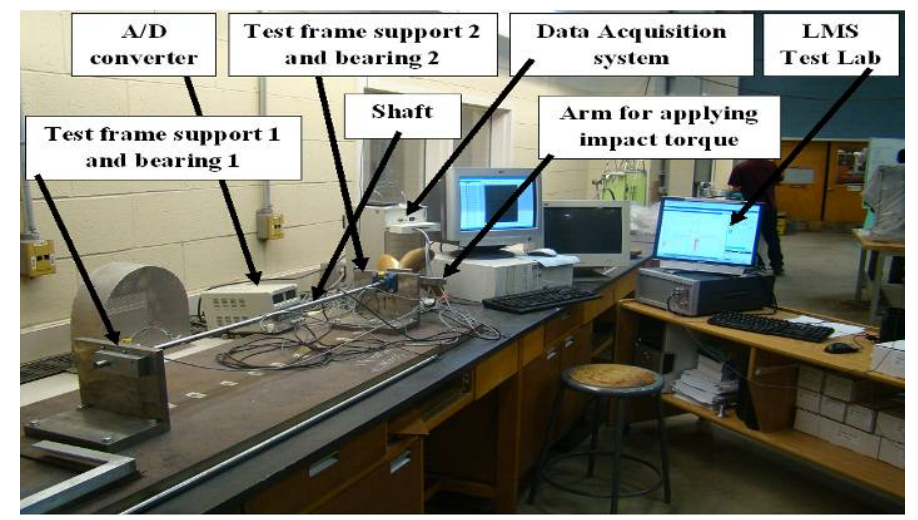

(a)

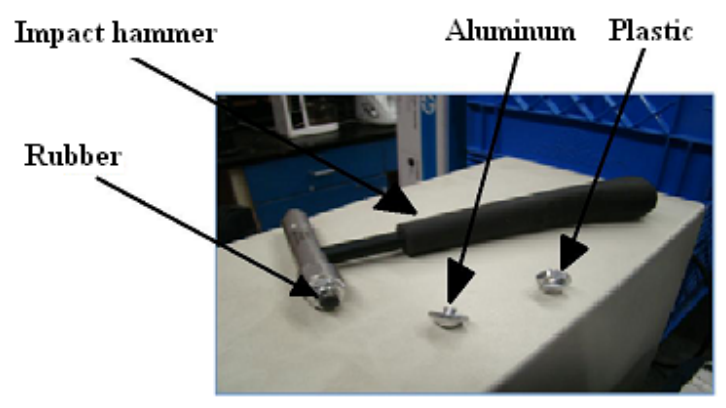

(b)

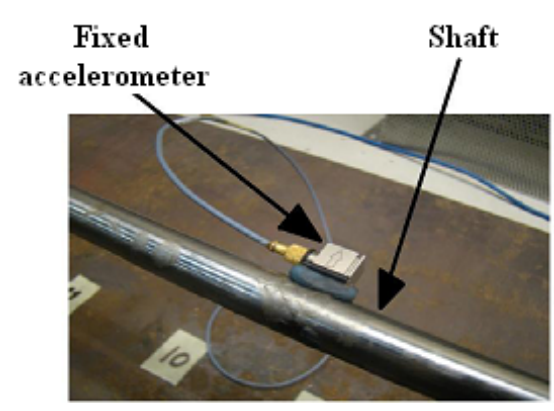

(c)

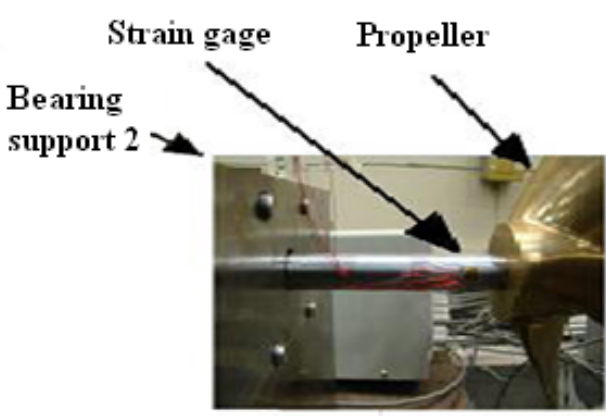

(d)

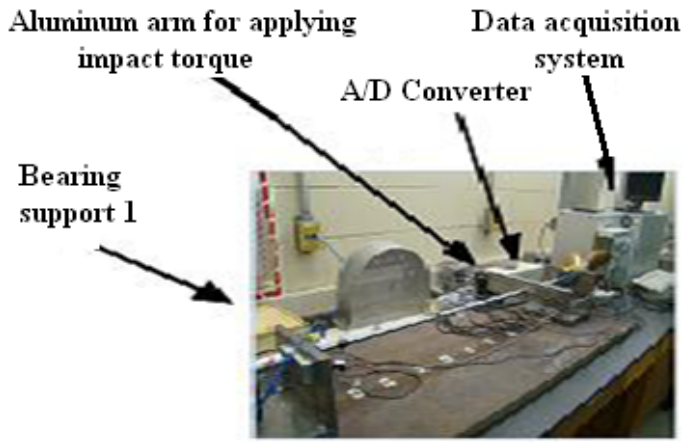

(e)

Figure 2. Schematics of the instrumentation equipment: a) LMS Test LAB with rotating shaft; b) Impact hammer and tips; c) Accelerometer device; d) Strain gage; and e) Data acquisition system 


\section{Modeling of Shaft-bearing Support}

The shaft was supported over two roller bearings supported by two fixed steel supports; the fixed steel supports were fixed-welded to the large steel base plate as shown in Figure 3(a). The steel base plate was fixed to the table at bottom.The bearing model used for the present study wasthe Flange Mounted McMaster-Carr Ball bearing (5967k81) shown in Figure 3 (McMaster-Carr, 2011)shown in Figure 3(b). It contains two main parts, viz., the inner and outer housing bearing surfaces connected together through some balls; and two tight screwsthat connected the shaft to the inner bearing.
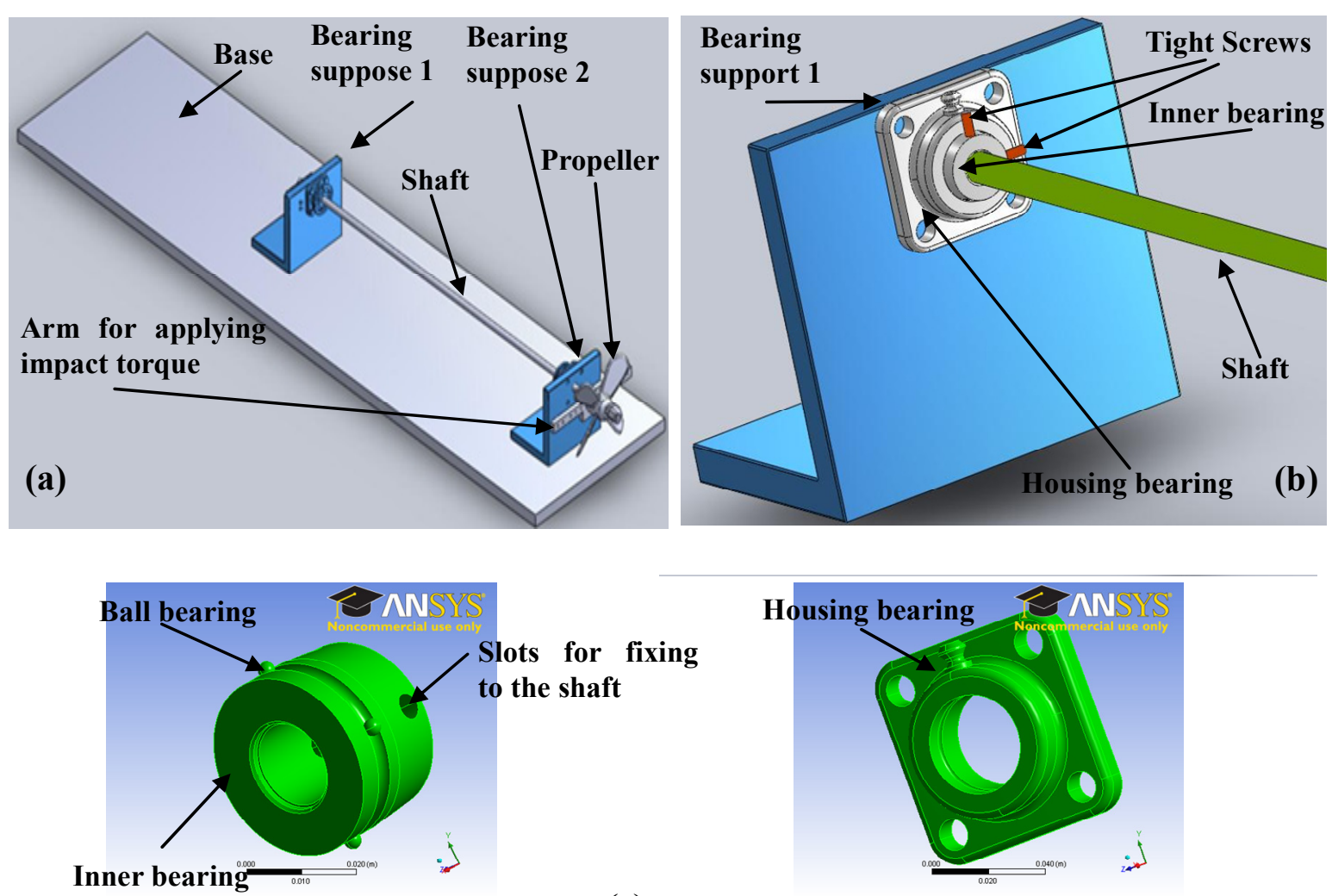

(c)

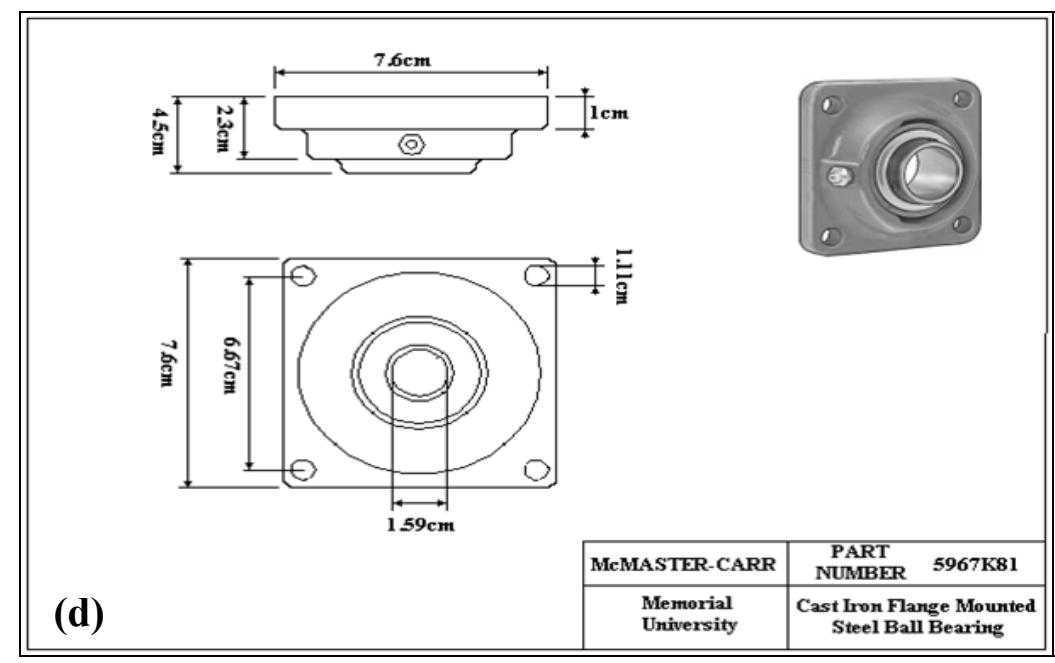

Figure 3. a) Details of bearing support; b) Schematic diagram of shaft-propeller-bearing; c) Inner and outer bearing; and d) Dimensions of mounted bearing 


\subsection{Elements Used in Analysis}

In this paper, the Finiteelement software program ANSYS Workbench 13 was used to create 3-D analytical models of the propeller-shaft system. The element types used for the 3-D model were chosen automatically (Huei, 2011) by default from the element library by the Workbench according to the types of the structural bodies used in the analysis. It usestwo types of elements (see Figure 4), viz., (i) Solid 186, which is a second order 3-D, 20-node element which can degenerate to a hexahedral triangle-based prism, or a quadrilateral-based pyramid, or a tetrahedron; and (ii) Solid 187, which is a3-D 10-node tetrahedral second order structural solid element. Each node for both types of element has three degrees of freedom (translations in the $\mathrm{x}, \mathrm{y}$, and $\mathrm{z}$ directions).

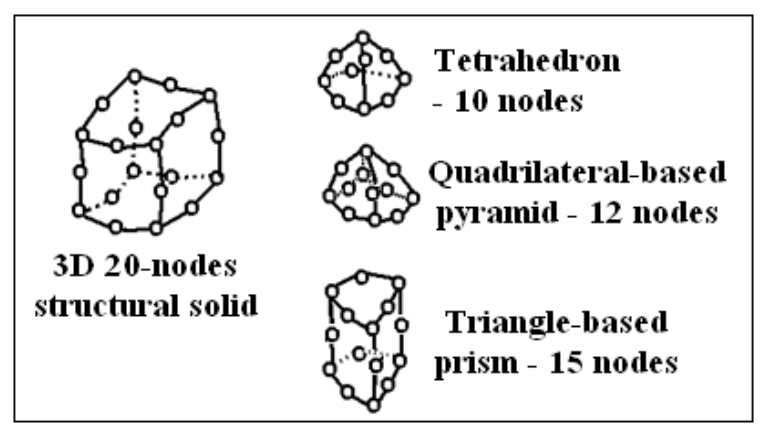

Figure 4. Geometries of the elements

\subsection{Mesh Convergence Study and Geometry}

Commercial FE software ANSYS with Workbench was utilized to carry out the modeling and frequency analysis of circular shafts supported on bearings. A mesh convergence study was carried outearlier so as to ensure that the values of the experimental natural frequencies for lateral and torsional were convergent with numerical results. Several mesh sizes (with maximum element dimensions varying from $0.7 \mathrm{~cm}$ to $2.0 \mathrm{~cm}$ ) of the model were utilized in this study. The shaft-propeller-bearing configuration and mesh generation are shown in Figure 5(a). The mesh convergent study carried out showed that the frequency responses werevery close to the experimental results for a mesh size of $1.0 \mathrm{cmfor}$ the shaft system. The model had 39731 elements and 78580 nodes for the un-cracked shaft. For the cracked shaft the same mesh was used with refinement of the mesh around the crack front giving a much higher number of elements and nodes for the vibrating system. The mesh around the crack region is shown in Figure 5(b).

\subsection{Contact Behavior}

In ANSYS workbench the contact between two bodies were represented by two contact surfaces, one specified as a contact surface and the other as a target surface. The contact between these bodies can be represented by one of the following types, viz., bonded, frictional, frictionless, rough, and no separation. Bonded contact means that the two bodies were integral with one another and act as a single body. Frictional contact applies only to surfaces in contact and the value of friction varies from a low value to a high value (only positive values were permitted). Rough contact represents the surfaces which have a very large friction coefficient between the contacting bodies. In the present shaft-propeller system, all the three types of contact have been used. It can be explained as follows: (i) The parts which were bonded together are, viz., two tight screws to inner bearing and to shaft, housing bearing to inner connection (a part that is made to fill the space between the bearing surfaces and the steel supports, to avoid unwanted zero modes), housing bearing to balls, shaft to small nut, shaft to big nut, shaft to fixed aluminum, propeller to small nut, small nut to big nut, and fixed aluminum to support 1; (ii) The parts which had frictional contacts were, viz., aluminum arm to shaft (friction coefficient is 0.2 ), aluminum arm to propeller (friction coefficient is 0.1), inner connection to support (friction coefficient is 0.001 ), and shaft to propeller (friction coefficient is 0.1 ); and (iii) The parts which had frictionless contacts were, viz., housing bearing to inner bearing, balls to inner bearing, balls to inner connections, inner bearing to inner connections, inner bearing to shaft, inner connections to shaft, fixed aluminum to support 1 and shaft to support 1 . The frictional coefficient became important in determining the correct torsional frequency since the propeller was not welded tothe shaft, but joined rigidly through a slotted keyway system. The frictional coefficient that gave frequencies close to the experimental values was used to get the correct numerical values. The same consideration was used in identifying the frictional coefficient for the torque arm. 

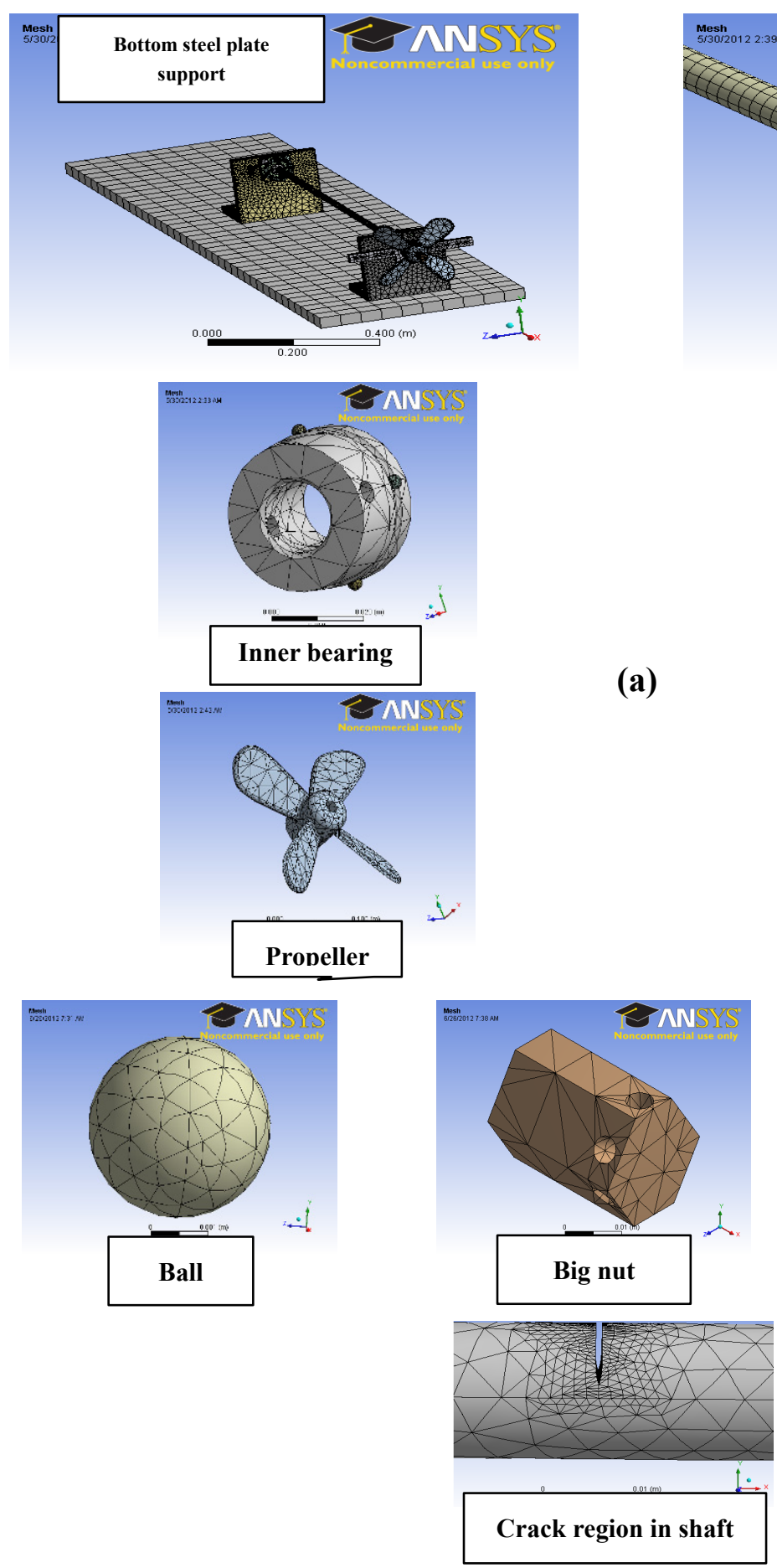

(a)
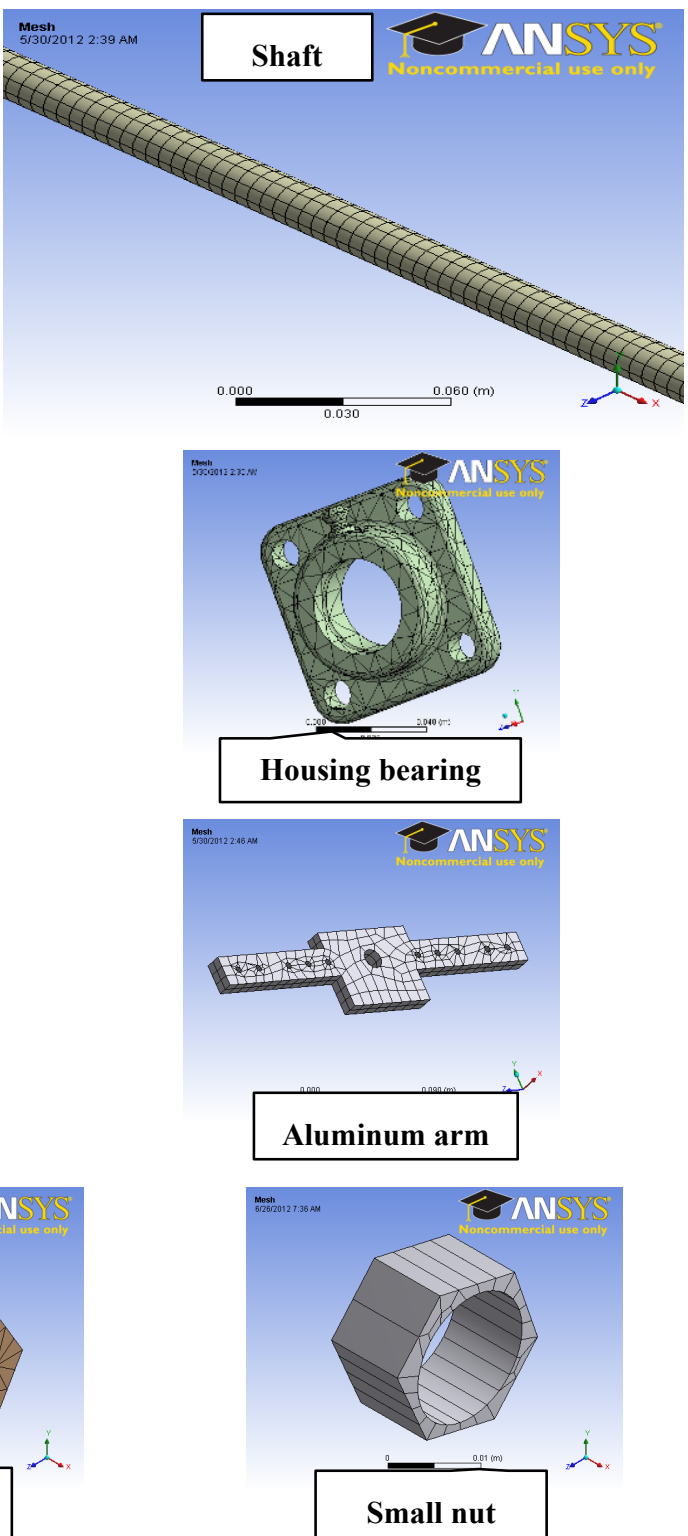

(b)

Figure 5. a) Finite Element mesh used for the various components of the rotating shaft system; and b) Mesh around the crack region

\subsection{Materials}

The shaft-bearing-system model contained different type of materials. As mentioned in the previous section the model had several interconnecting parts such as shaft, propeller, bearings, nuts, tight screws, aluminum arm, fixed aluminum, support, and inner connection. The material properties of these parts used in the analysis are summarized in Table 1. 
Table 1. Material properties used for the numerical modal

\begin{tabular}{ccccccc}
\hline Type & Material & $\begin{array}{c}\text { Density } \\
\mathrm{Kg} / \mathrm{m}^{3}\end{array}$ & $\begin{array}{c}\text { Modulus of } \\
\text { elasticity } \\
\mathrm{Pa}\end{array}$ & $\begin{array}{c}\text { Poisson's } \\
\text { ratio }\end{array}$ & $\begin{array}{c}\text { Bulk } \\
\text { ModulusPa }\end{array}$ & $\begin{array}{c}\text { Shear } \\
\text { ModulusPa }\end{array}$ \\
\hline shaft & Steel & 7850 & $2 \mathrm{e}+11$ & 0.3 & $1.67 \mathrm{e}+11$ & $7.69 \mathrm{e}+10$ \\
$\begin{array}{c}\text { Propeller } \\
\text { Support }\end{array}$ & Bronze & 8800 & $1.14 \mathrm{e}+11$ & 0.34 & $1.19 \mathrm{e}+11$ & $4.25 \mathrm{e}+10$ \\
$\begin{array}{c}\text { Housing } \\
\text { bearing }\end{array}$ & Greel & 7850 & $2 \mathrm{e}+11$ & 0.3 & $1.67 \mathrm{e}+11$ & $7.69 \mathrm{e}+10$ \\
$\begin{array}{c}\text { Inner bearing } \\
\text { Fixed }\end{array}$ & Structural steel & 7850 & $2 \mathrm{e}+11$ & 0.3 & $1.67 \mathrm{e}+11$ & $7.69 \mathrm{e}+09$ \\
$\begin{array}{c}\text { aluminum } \\
\text { Aluminum arm }\end{array}$ & Aluminum Alloy & 2770 & $7.1 \mathrm{e}+10$ & 0.33 & $6.96 \mathrm{e}+10$ & $2.67 \mathrm{e}+10$ \\
$\begin{array}{c}\text { Inner } \\
\text { connection }\end{array}$ & $\begin{array}{c}\text { Aluminum Alloy } \\
\text { Artificial }\end{array}$ & 2770 & $7.1 \mathrm{e}+10$ & 0.33 & $6.96 \mathrm{e}+10$ & $2.67 \mathrm{e}+10$ \\
$\begin{array}{c}\text { pight screws } \\
\text { Small and big }\end{array}$ & polyethylene & 50 & $1.1 \mathrm{e}+05$ & 0.42 & $2.29 \mathrm{e}+05$ & 38732 \\
nut & steel & 7850 & $2 \mathrm{e}+11$ & 0.3 & $1.67 \mathrm{e}+11$ & $7.69 \mathrm{e}+10$ \\
\hline
\end{tabular}

\section{Presentation of Results and Discussion}

In this part, results obtained from the finite element software program (using ANSYS workbench 13) and from experimental program are presented. These results give the eight lowest bending frequencies (four vertical and four horizontal) and mode shapesof the un-cracked and cracked shafts. For experimental and numerical studies, one crack position and various crack ratios (from $0 \%$ to $70 \%$ ratio) were examined. Table 2 shows the results of the first eight natural bending frequencies (four vertical and four horizontal); it also gives the computed torsional frequency. These experiments were repeatedfor three different shaft-bearing systems, viz., shaft No. 1, shaft No.2 and shaft No. 3. The three shafts were of almost of the same diameter (average measured diameter values were $0.01588 \mathrm{~m}, 0.01586 \mathrm{~m}, 0.01589 \mathrm{~m}$, respectively). For each crack depth three independent tests were carried out and the results processed through the LMS Test Lab system. Then the results were added and averaged to get the final result reported herein.The experimental and numerical results seem to be agreeing very well (in a non-dimensional manner) with one another as the crack depth increases in the shaft-propeller-bearing system; in both experimental and numerical results, the frequencies of the cracked shaft clearly decrease as the crack depth increases. Also the estimated numerical values of frequencies have been observed to be higher than the measured experimental ones for the fundamental frequency. The experimental and numerical results are extremely consistent as the crack depth increases in the shaft-propeller system; the frequencies of the cracked shaft progressively decrease as the crack depth increases, in both experimental measurements and numerical computations. Also the experimental measurements of frequency changes have been observed to be higher than the numerically estimated values for all the frequencies. One probable reason for this difference is that the numerical changes shown by FE procedure seems to under estimate the changes taking place at the crack location.

Also the measured frequency differences between successive crack profiles used in the study are many times less than 0.1 to $0.2 \mathrm{~Hz}$. It has also been estimated from the given digitization rate of the experiments, that the accuracy of frequency measurements is around $0.25 \mathrm{~Hz}$. This is in correspondence with the limitations in the ANSYS software for FRF computations where the minimum frequency difference was $0.25 \mathrm{~Hz}$. Hence the measured changes would reflect these limitations in the changes that occur in measuring the successive cracks profiles used in the study.

Table 3 shows the measurements made to relate the experimental torsional frequency with detailed experimental test measurements and theoretical calculation made for computing the torsional frequency. It can be observed from Table 3 that the error is less than $1.57 \%$ between analytical and experimental values. These results indicate that the experimental measurements compare well with theoretical and numerical computations. 
Table 2. Experimental and numerical values of natural frequencies for various crack dept ratios (V - vertical and $\mathrm{H}$ - horizontal and torsional)

\begin{tabular}{|c|c|c|c|c|c|c|c|c|c|}
\hline & & \multicolumn{8}{|c|}{ Crack depth ratios } \\
\hline \multirow{2}{*}{\multicolumn{2}{|c|}{ Frequency }} & \multicolumn{2}{|c|}{$0.0 \%$} & \multicolumn{2}{|c|}{$10 \%$} & \multicolumn{2}{|c|}{$20 \%$} & \multicolumn{2}{|c|}{$30 \%$} \\
\hline & & $\mathrm{V}$ & $\mathrm{H}$ & $\mathrm{V}$ & $\mathrm{H}$ & $\mathrm{V}$ & $\mathrm{H}$ & $\mathrm{V}$ & $\mathrm{H}$ \\
\hline \multirow{4}{*}{ First } & Exp. Shaft $1^{*}$ & 34.768 & 41.344 & 34.417 & 41.544 & 34.119 & 41.182 & 34.325 & 41.196 \\
\hline & Exp. Shaft $2^{*}$ & 36.395 & 42.980 & 36.315 & 42.959 & 36.262 & 42.904 & 36.212 & 42.91 \\
\hline & Exp. Shaft $3^{*}$ & 33.855 & 40.629 & 33.774 & 40.656 & 33.751 & 40.615 & 33.736 & 40.550 \\
\hline & Num. Comp. & 35.577 & 41.182 & 35.594 & 41.113 & 35.551 & 41.173 & 35.471 & 41.107 \\
\hline \multirow{4}{*}{ Second } & Exp. Shaft $1^{*}$ & 76.78167 & 78.279 & 76.413 & 78.57567 & 76.05867 & 78.31 & 75.205 & 78.02033 \\
\hline & Exp. Shaft $2^{*}$ & 75.975 & 80.034 & 76.056 & 79.985 & 75.852 & 79.903 & 75.617 & 79.309 \\
\hline & Exp. Shaft $3^{*}$ & 74.614 & 79.914 & 74.593 & 79.809 & 74.487 & 79.844 & 74.215 & 79.826 \\
\hline & Num. Comp. & 75.247 & 78.245 & 75.113 & 78.102 & 75.021 & 78.017 & 74.933 & 78.129 \\
\hline \multirow{4}{*}{ Third } & Exp. Shaft $1^{*}$ & 190.634 & 199.089 & 190.757 & 197.944 & 189.998 & 197.769 & 189.865 & 197.829 \\
\hline & Exp. Shaft $2^{*}$ & 196.119 & 199.544 & 195.849 & 199.462 & 195.667 & 199.503 & 195.398 & 199.424 \\
\hline & Exp. Shaft $3^{*}$ & 192.190 & 197.813 & 191.962 & 197.817 & 191.742 & 197.771 & 191.298 & 197.652 \\
\hline & Num. Comp. & 187.880 & 199.22 & 187.51 & 198.97 & 187.43 & 198.82 & 187.4 & 199.4 \\
\hline \multirow{4}{*}{ Fourth } & Exp. Shaft $1^{*}$ & 365.8 & 335.241 & 364.3547 & 335.2313 & 362.3233 & 335.7223 & 365.426 & 336.0583 \\
\hline & Exp. Shaft $2^{*}$ & 367.423 & 369.148 & 366.861 & 368.992 & 366.391 & 368.896 & 365.457 & 368.605 \\
\hline & Exp. Shaft $3^{*}$ & 352.959 & 355.931 & 353.392 & 355.628 & 352.642 & 355.315 & 349.39 & 353.132 \\
\hline & Num. Comp. & 360.1 & 381.49 & 358.72 & 380.75 & 358.99 & 380.58 & 362.09 & 383.3 \\
\hline \multirow{2}{*}{$\begin{array}{l}\text { First natural } \\
\text { frequency for } \\
\text { torsion }\end{array}$} & Exp. Shaft 1 & \multicolumn{2}{|c|}{43.716} & \multicolumn{2}{|c|}{43.213} & \multicolumn{2}{|c|}{42.826} & \multicolumn{2}{|c|}{42.628} \\
\hline & Num. Comp. & \multicolumn{2}{|c|}{43.453} & \multicolumn{2}{|c|}{43.422} & \multicolumn{2}{|c|}{43.111} & \multicolumn{2}{|c|}{42.92} \\
\hline \multirow{3}{*}{\multicolumn{2}{|c|}{ Frequency }} & \multicolumn{8}{|c|}{ Crack depth ratios } \\
\hline & & \multicolumn{2}{|c|}{$0.40 \%$} & \multicolumn{2}{|c|}{$50 \%$} & & & & \\
\hline & & $\mathrm{V}$ & $\mathrm{H}$ & $\mathrm{V}$ & $\mathrm{H}$ & $\mathrm{V}$ & $\mathrm{H}$ & $\mathrm{V}$ & $\mathrm{H}$ \\
\hline & Exp. Shaft ${ }^{*}$ & 33.80933 & 41.09267 & 33.79633 & 40.815 & 32.64033 & 40.52267 & 30.60033 & 39.84867 \\
\hline & Exp. Shaft $2^{*}$ & 36.02723 & 42.77933 & 35.791 & 42.70067 & 35.21133 & 42.23533 & 33.98633 & 41.728 \\
\hline First & Exp. Shaft $3^{*}$ & 33.54967 & 40.47867 & 33.335 & 40.339 & 32.80367 & 40.03433 & 31.67467 & 39.535 \\
\hline & Num. Comp. & 35.402 & 41.575 & 34.922 & 41.002 & 34.23 & 40.497 & 33.706 & 40.583 \\
\hline & Exp. Shaft $1^{*}$ & 75.48633 & 77.35933 & 74.19133 & 76.54333 & 72.79567 & 76.23 & 67.299 & 74.95233 \\
\hline & Exp. Shaft $2^{*}$ & 74.99833 & 79.09533 & 74.20733 & 79.09067 & 72.38067 & 79.03467 & 69.24733 & 77.91233 \\
\hline Second & Exp. Shaft $3^{*}$ & 73.44333 & 79.603 & 72.554 & 79.372 & 70.73833 & 78.92633 & 67.54433 & 77.9527 \\
\hline & Num. Comp. & 74.27 & 77.997 & 73.48 & 77.79 & 71.832 & 76.594 & 69.705 & 76.879 \\
\hline & Exp. Shaft $1^{*}$ & 189.449 & 197.708 & 188.0927 & 197.1897 & 186.1117 & 196.4363 & 178.986 & 195.956 \\
\hline & Exp. Shaft $2^{*}$ & 194.5687 & 199.3333 & 193.421 & 199.0703 & 190.7537 & 198.4617 & 185.5763 & 197.3003 \\
\hline Third & Exp. Shaft $3^{*}$ & 190.0337 & 197.4143 & 188.644 & 197.0687 & 185.412 & 196.3743 & 180.0857 & 195.0663 \\
\hline & Num. Comp. & 186.4 & 198.66 & 185.56 & 198.76 & 183.36 & 197.05 & 179.87 & 196.46 \\
\hline & Exp. Shaft $1^{*}$ & 358.8217 & 335.4333 & 355.349 & 333.2633 & 345.0703 & 331.14 & 327.8163 & 321.8417 \\
\hline & Exp. Shaft $2^{*}$ & 362.876 & 367.6683 & 359.1237 & 366.059 & 349.9673 & 362.3057 & 333.337 & 354.9043 \\
\hline Fourth & Exp. Shaft $3^{*}$ & 344.4017 & 350.252 & 339.052 & 347.5507 & 328.8137 & 343.1973 & 315.164 & 336.204 \\
\hline & Num. Comp. & 379.14 & 360.66 & 360.66 & 380.83 & 341.77 & 376.87 & 338.83 & 366.55 \\
\hline First natural & Exp. Shaft 1 & & & 41. & & 41 & & & \\
\hline $\begin{array}{l}\text { frequency for } \\
\text { torsion }\end{array}$ & Num. Comp. & 42 & & 42 & & & & & \\
\hline
\end{tabular}

"Average of three independent measurements.

Table 3. Theoretical and experimental values of mass moment of inertia and torsional natural frequencies

\begin{tabular}{|c|c|c|c|c|c|c|}
\hline \multicolumn{2}{|c|}{$\begin{array}{l}\text { Mass moment of inertia for } \\
\text { platform, kg. } \mathrm{m}^{2}\end{array}$} & \multirow{2}{*}{ 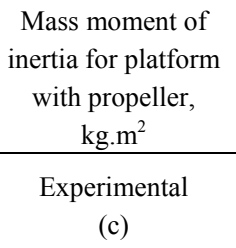 } & \multirow{2}{*}{$\begin{array}{l}\begin{array}{c}\text { Mass moment of } \\
\text { inertia for } \\
\text { propeller, kg.m }\end{array} \\
\begin{array}{c}\text { Experimental } \\
(d)=(c)-(b)\end{array}\end{array}$} & \multirow{2}{*}{$\begin{array}{c}\text { Total mass moment } \\
\text { of inertia }(\text { propeller } \\
+\begin{array}{c}\left.\text { plate }^{*}+\text { shaft }^{* *}\right), \\
\text { kg.m }{ }^{2}\end{array} \\
\begin{array}{c}\text { Theoretical and } \\
\text { experimental }\end{array}\end{array}$} & \multicolumn{2}{|c|}{$\begin{array}{l}\text { Torsional natural frequency for } \\
\text { un-cracked shaft } w_{n}, \mathrm{~Hz}\end{array}$} \\
\hline $\begin{array}{l}\text { Theoretical } \\
\text { (a) }\end{array}$ & $\begin{array}{l}\text { Experimental } \\
\text { (b) }\end{array}$ & & & & Theoretical & Experimental \\
\hline $7.746 \times 10^{-3}$ & $7.571 \times 10^{-3}$ & $1.163 \times 10^{-2}$ & $4.057 \times 10^{-3}$ & $5.639 \times 10^{-3}$ & 43.04 & 43.72 \\
\hline
\end{tabular}

* Jplate $=1.5232 \times 10^{-3} \mathrm{~kg} . \mathrm{m}^{2}$ (by experimental measurements); ** Jshaft $=1.5232 \times 10^{-3} \mathrm{~kg} \cdot \mathrm{m}^{2}$ (by theory). 
Figure 6(a) and (b) showsthe mode shapes comparison for first eight natural frequencies of (four vertical and four horizontal) experimental and numerical analyses. As could be observed from the plots shown in Figures 6(a) and (b), the experimental measurements closely correspond with the numerical computations. In the numerical computations the local propeller blade responses were observed to lie between the $3^{\text {rd }}$ and $4^{\text {rd }}$ vertical bending frequencies. In addition the support bending vibrations were observed to be above the $4^{\text {rd }}$ horizontal bending frequency.

Figure 7 shows the changes that occur in the experimental bending and torsional frequencies as the crack depth ratios change from 0 to $70 \%$ (cubic curve fit). It can be seen that the frequency changes become appreciable only when the crack depth ratio is more than $50 \%$. This would lead to a precipitous cracking of the shaft unless it is noticed in a timely manner. Hence another type of measure is required to detect the presence of cracking damage in cylindrical shafts. When the rate of change of frequency is plotted as a function of crack depth ratio, as shown in Figure 8(a) - (d), the abrupt changes in plots can be observed even for a crack depth ratio of $20 \%$ or greater. This was observed earlier by (Hamidi, Piaud, \& Massoud, 1992), who stated that the rate of change in natural frequencies become observable when the crack depth ratio becomes greater than 0.30 .

Also in Figure 8 (a) the plot of the depth of crack and rate of change in torsional frequency shows a significant difference from that of the bending frequencies. It shows that the rate of change in the torsional frequency gives a much better indication of the crack presence, especially during the starting point of the crack. It is seen that the rate of change of the expt. torsional frequency vs. crack depth ratio is much higher (at the crack depth ratios of $10 \%, 20 \%$ and $30 \%$, the rate of change of frequency with respect to crack depth ratios are correspondingly $8 \%$, $12 \%$ and $11 \%$ ) whereas the rate of change of bending frequencies during the earlier stage of crack initiation and growth is much less (at the above crack depth ratios the rate of change of frequency with respect to crack depth ratio are varying between $2 \%$ to $5 \%$ - see Figure $8(\mathrm{a})$ ). This could be easily understood since the influence of cracking on torsional inertia (due to its larger influence alongthe skin surface of the cylindrical shaft than its depth) will be much higher than the bending inertia and the consequent changes in the rate of frequency change. Hence the rate of change of torsional frequency (with respect to crack depth ratio) could very well be used as a very good indicator of the presence of any small crack. More experimental measurements are needed to confirm the above findings.

Figure 9 shows the responses of the system under test (impact excitation) and the corresponding responses functions (acceleration FRFs, velocity FRFs, displacement FRFs) for experimental and numerical results. Frequency response functions for various crack depth ratios (from $0 \%$ to $70 \%$ ratio) were obtained for all cases. All figures illustrate the frequency shifts that occur due to the increased cracking in the shaft. It is also observed for all cases (experimental and numerical), reasonable agreements exist between numerical and experimental results. It can be seen from these figures, that the acceleration, velocity and displacement response functions (ARFs, VRFs and DRFs) can also be used as another tool for crack identification. Figure 10 shows individual comparisons for some cases (intact ARFs, VRFs and DRFs; cracked 20\% ARFs, VRFs and DRFs; cracked 40\% ARFs, VRFs and DRFs; and cracked 70\% ARFs, VRFs and DRFs.) for response functions of experimental and numerical computations. It can be seen more clearly that the shifts of acceleration, velocity and displacement response peaks are dependent on the change in natural frequencies and are directly proportional to the severities of the crack.

It is essential to point out two limitations in all the numerical computations reported in this study: (i) It can be seen from the curves given in Figures 9 and 10 in this study there is an extra frequency observable (around 35.0 to $45.0 \mathrm{~Hz}$ ) in the experimental results, which is not observed in the numerical computations. This extra frequency was determined to be due to the presence of the effect of torsional rotation (especially at the fixed end near support 1) in the measurement of vertical displacements. In the numerical computations, the torsional and bending frequencies (as well as their response functions) could not be computed in a single numerical computation for the indeterminate shaft. It had to be computed in two separate computations where the shaft was permitted to either bend or rotate freely (over the support 2 near the overhang) by the provision of zero friction (boundary condition for torsion) at the support near the overhang; this led to two different systems. The torsional frequencies were obtained correctly, when zero friction was provided at bearing support 2 and the bending frequencies were correctly obtained when friction of bearing \# 2 was greater than zero $\left(>10^{-14}\right)$; and (ii) Also in the numerical computation for response functions the desired accuracy for computations could not be achieved with the provided computer memory size in the computing system. The accuracy with which the researcher could obtain response results was $0.25 \mathrm{~Hz}$ (one could solve results up to 1000 steps for the frequency range of zero to $250 \mathrm{~Hz}$ ). These two restrictions prevented better comparison to be obtained between experimental and numerical results. 

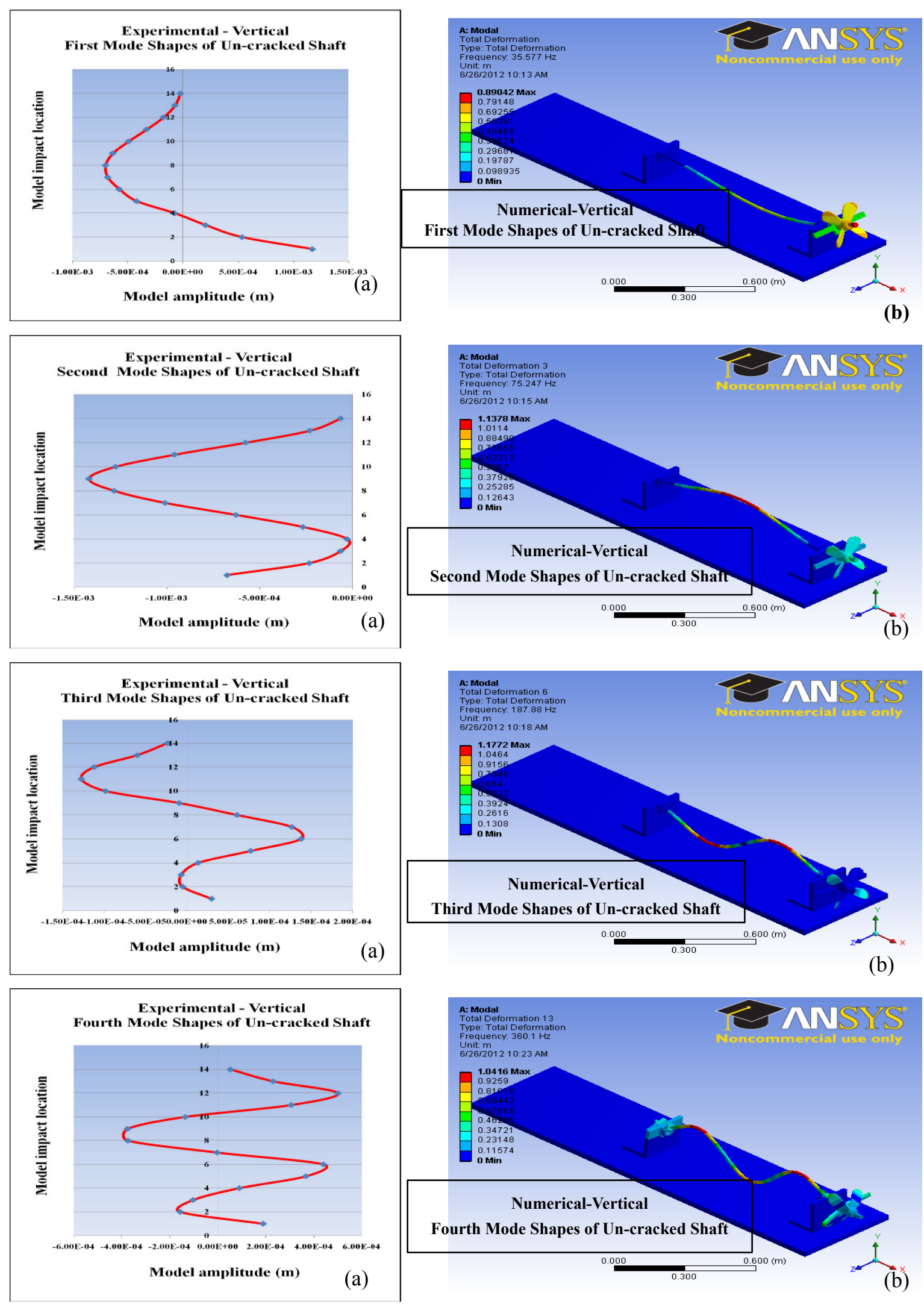

Figure 6(a). Mode shapes comparison for first four vertical frequencies: a) experimental and b) numerical 

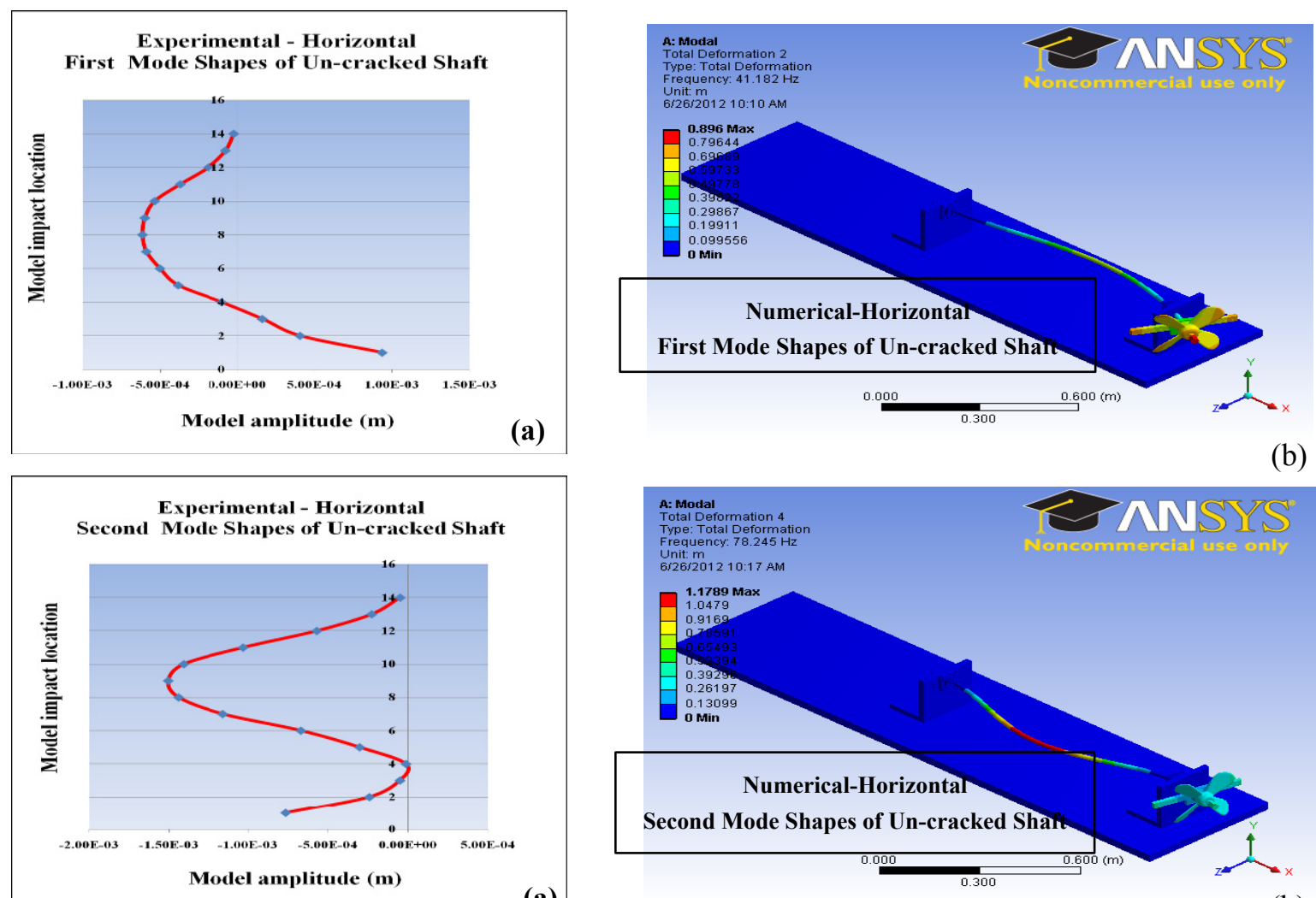

(a)

(b)
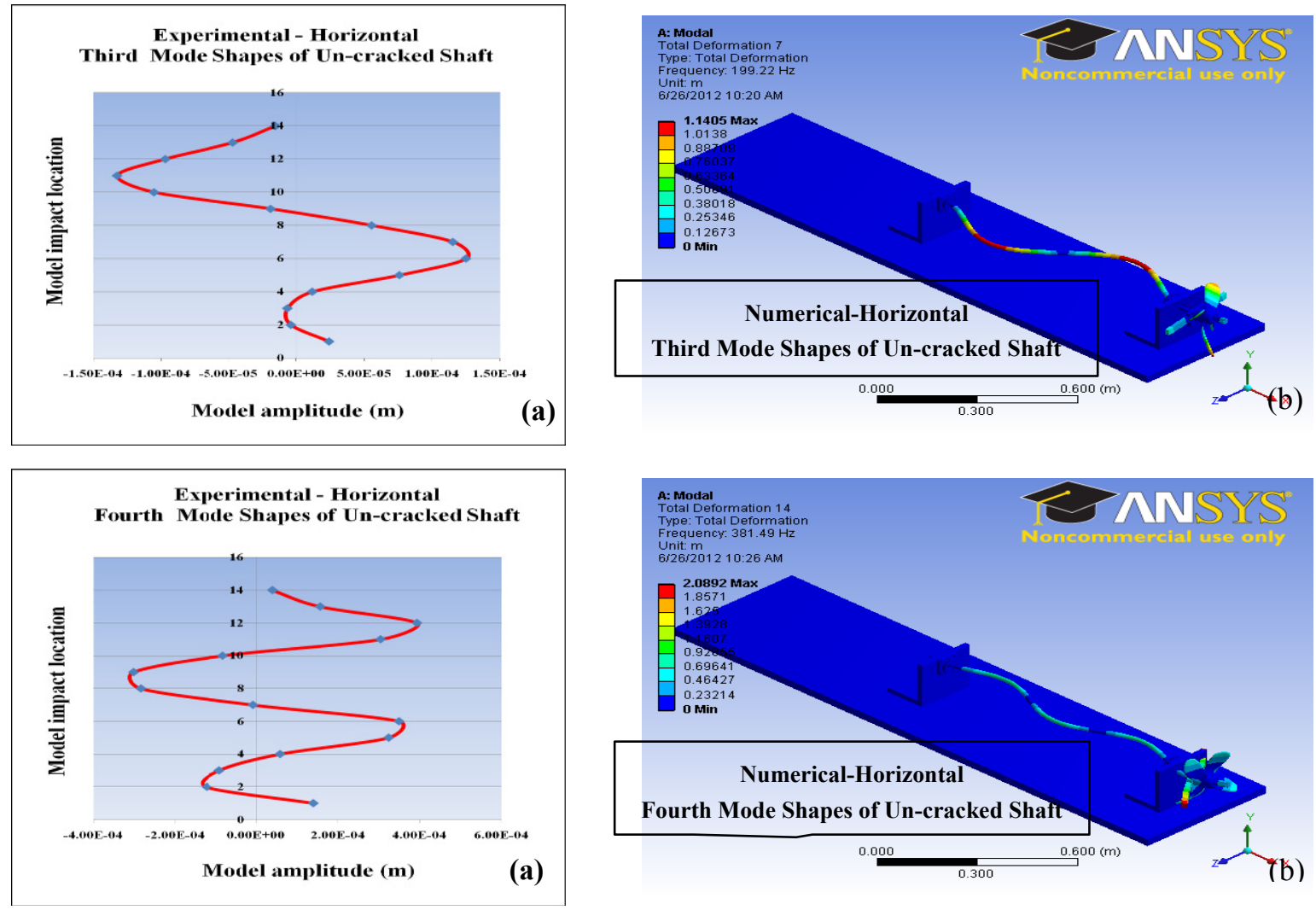

Figure 6 (b). Mode shapes comparison for first four horizontal natural frequencies:

a) experimental and b) numerical 


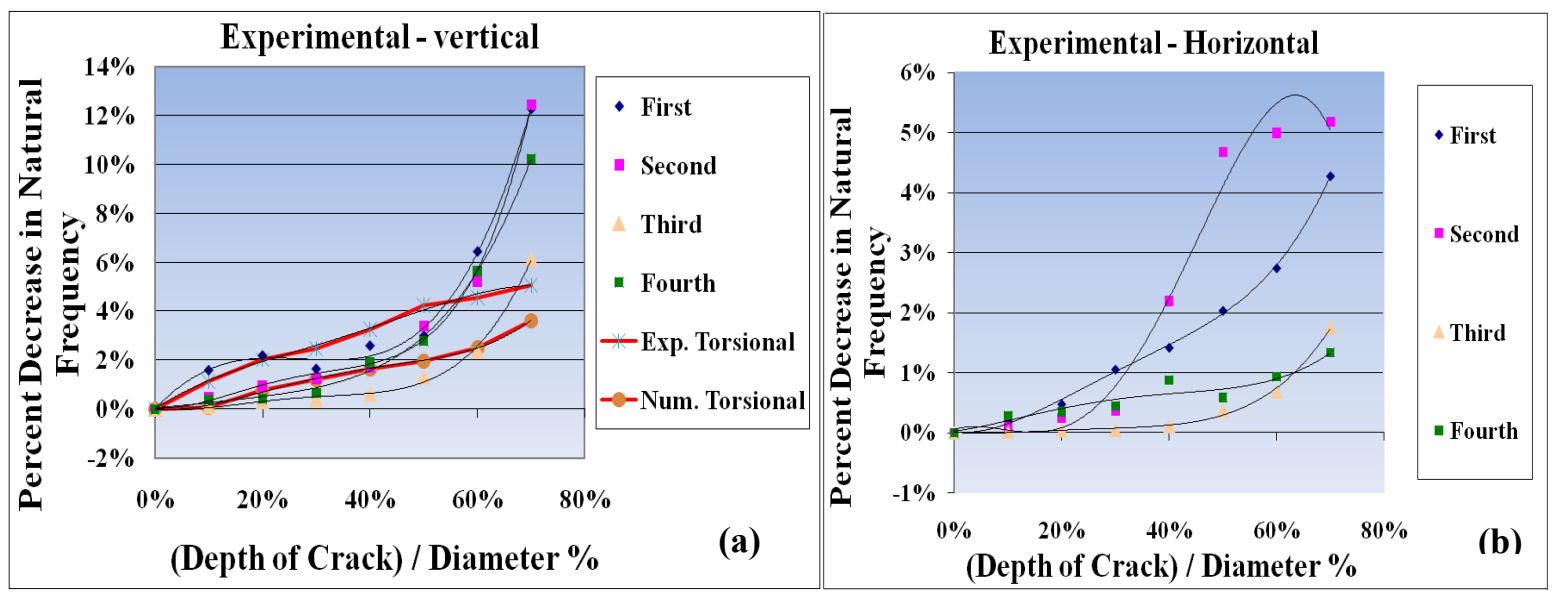

Figure 7. Depth of crack vs. percent decrease in bending and torsion natural frequencies for experimental results a) Vertical; b) Horizontal
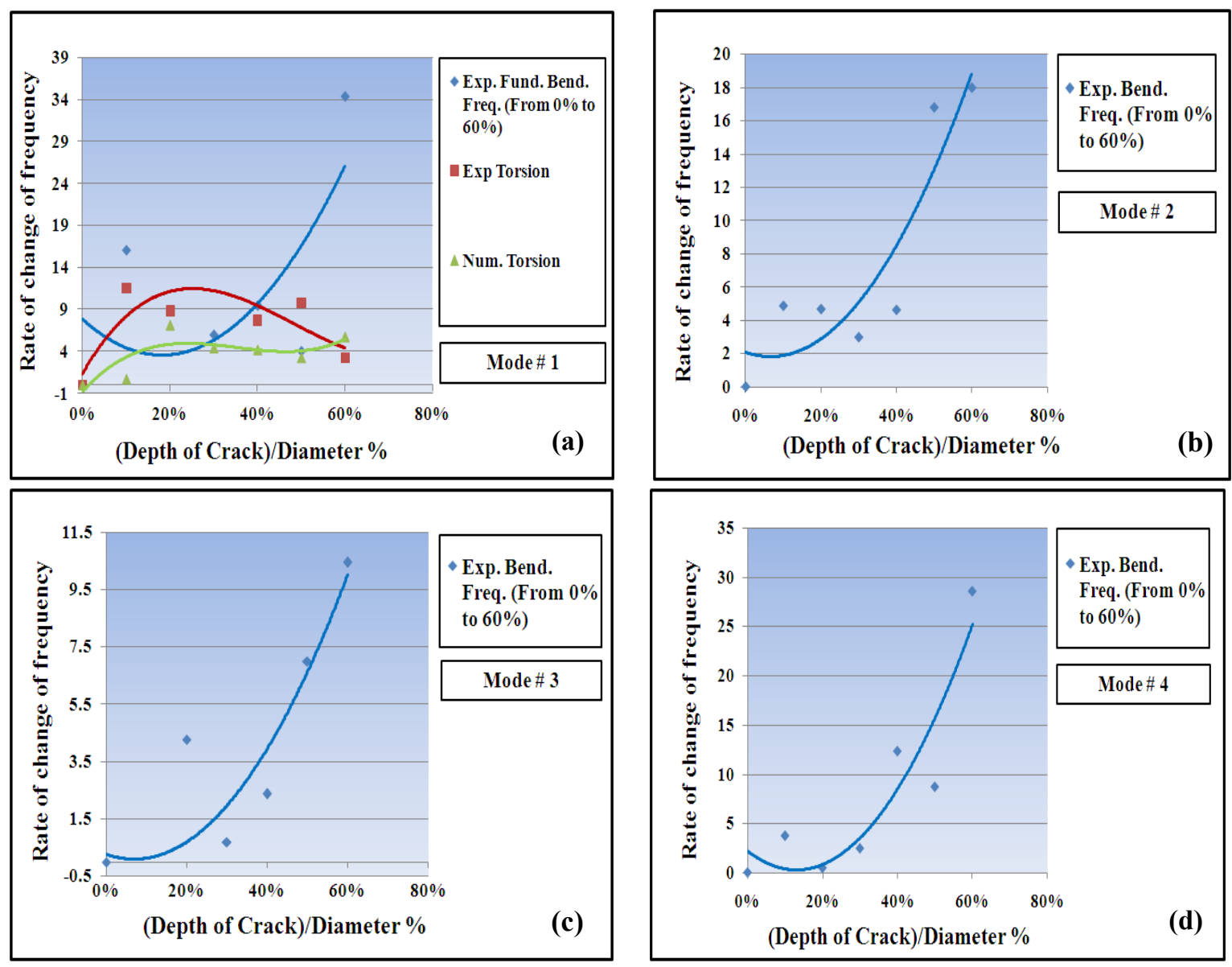

Figure 8. Rate of change of frequency (with respect to crack depth ratio) vs. crack depth ratio of the first four frequencies: a) Mode one; b) Mode two; c) Mode three; and d) Mode four 

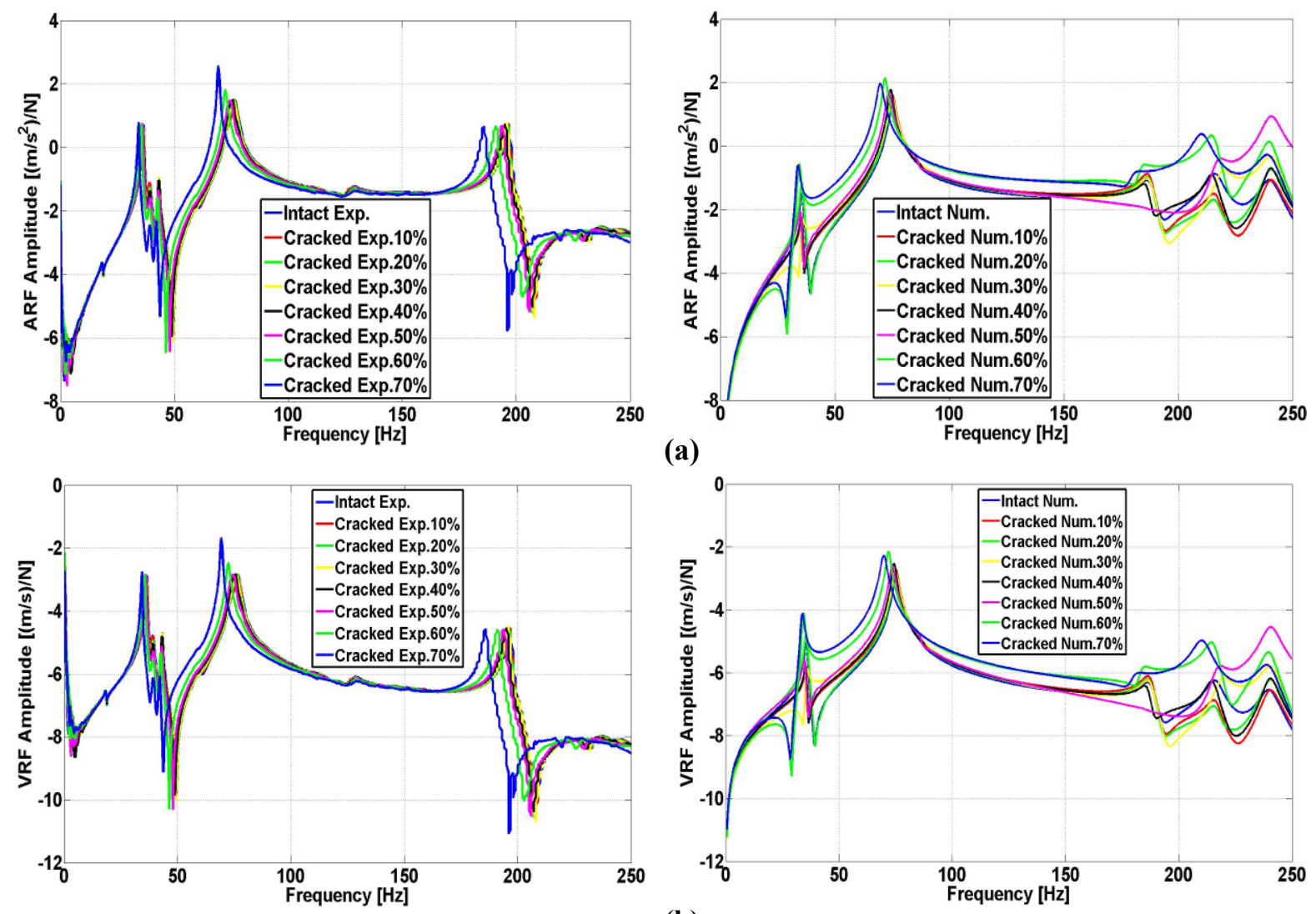

(a)

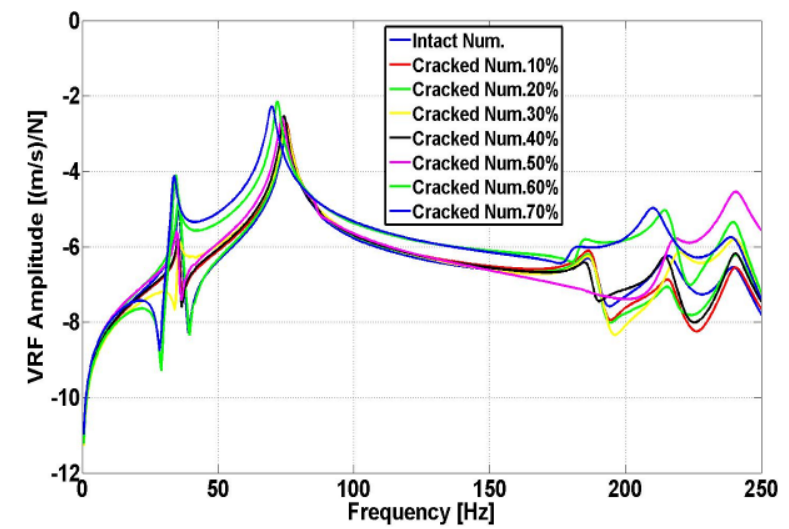

(b)
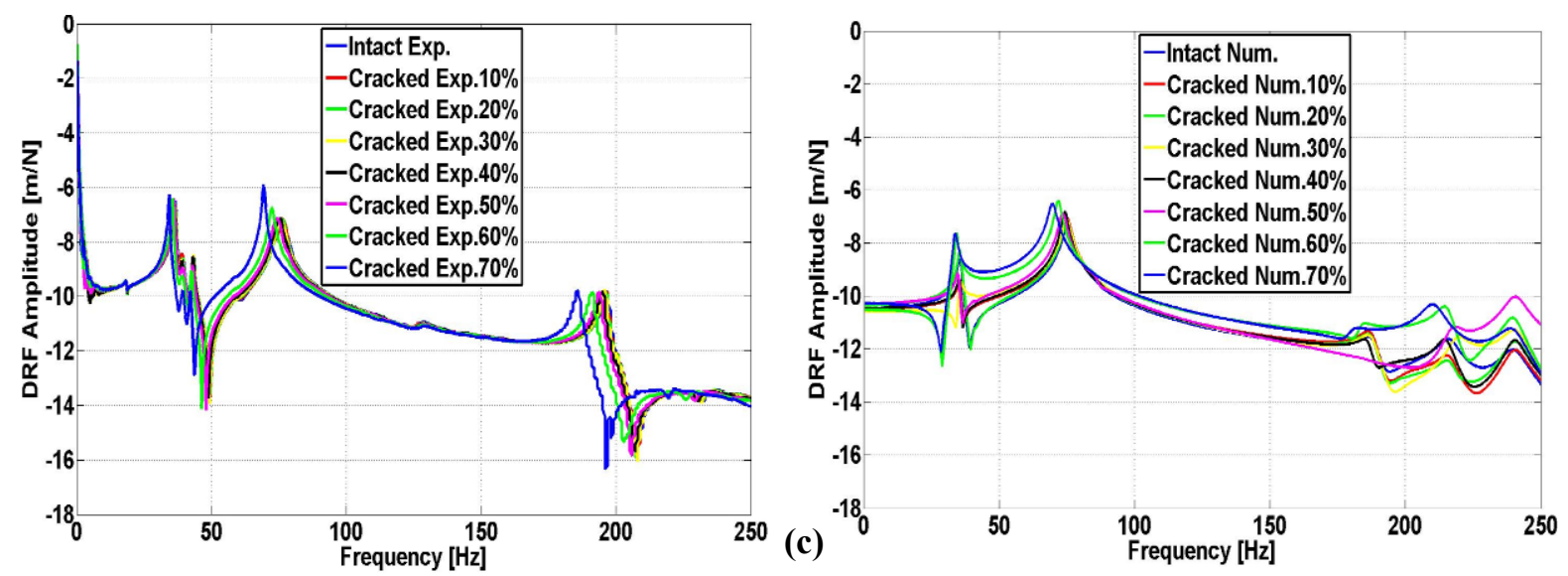

Figure 9. Schematic of experimental and numerical frequency response functions of: a) accelerations (ARFs); b) velocities (VRFs); and (c) displacements (DRFs) for shaft \# 2 

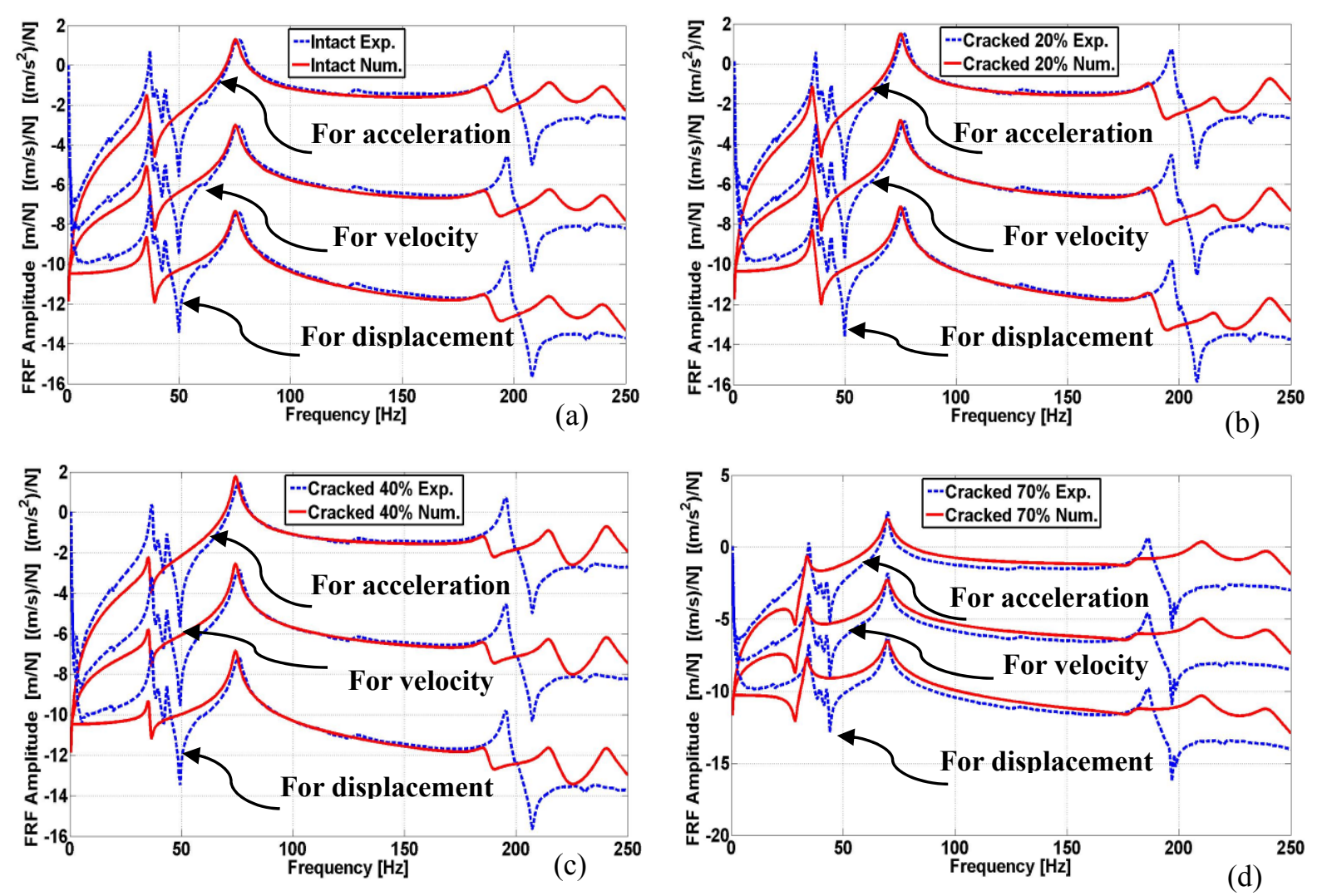

Figure 10. Schematic of frequency response functions for different depth of crack of experimental and numerical computations: a) Intact shaft; b) $30 \%$; c) $50 \%$; and d) $70 \%$

Figure 11(a), (c) and (e) show the changes that occur in the amplitude response and the slope (of amplitude response) for resonant frequencies (experimental results) as the crack depth ratio increases from 0.0 to 0.7 . Figure 11(a) shows the changes that occur in acceleration amplitude response vs. crack depth ratio. It is observedfrom this figure that the identifier of the mode shape change due to crack is shown better by the first mode shape than the second mode; the crack presence can be identifiedabove a crack depth ratio of 0.2 . Similarly, Figure 11(c) shows the changes that occur in velocity amplitude vs. crack depth ratio. In this figure the second mode gives a much better indication for the presence of crack than the first mode. Once again the crack presence can be identifiedbeyond a crack depth ratio of 0.2. Also Figure 11(e) shows the changes that occur in displacement amplituderesponse vs. crack depth ratio. These responses look like acceleration amplitude responses but may be less sensitive for crack. It can be seen from Figures 11(a) to (f) that the identification of crack can be observed with much better sensitivity from the velocity amplitude responses shown in Figure 11(c) and (d) (since the variation is much higher for velocity). In this case the crack can be identified after 0.2. Figure 11(b), (d) and (f) show the slope of the modal amplitudes for acceleration, velocity and displacement responses, respectively vs. crack depth ratio. Figure 11 (b) and (d) show that beyond the crack depth ratio of 0.2 , presence of the crack can be easily identified.

Figure 12(a), (c) and (e) show the changes that occur in the amplitude and the slope (of amplitudes) for anti-resonant frequencies (experimental results) as the crack depth ratio increases from 0.0 to 0.7 . Figures 12(a) and (e) show the changes that occur in acceleration amplitudes and displacement amplitudes vs. crack depth ratio, respectively. It is observed from the two figures that the crack can be identified after a crack depth ratio of 0.4 ; mode shape change due to crack is shown better by the third mode amplitude shape than the first mode amplitude shape. By comparing these anti-resonant figures and the previous ones, it is clear that the resonant frequency gives a much better indicator for the crack presence than the anti-resonant frequency. On the other hand Figure 12(c) for first mode gives a very good indicator for the crack presence than all other figures; hence the changes that occur in velocity amplitudes vs. crack depth ratiois much better than acceleration or displacement amplitudes. Figure 12(b), (d) and (f) show the slope of the anti-resonant modal amplitude for acceleration, velocity and displacement, respectively vs. crack depth ratio. Figure 12(b) shows that beyond a crack depth ratio of 0.3 , presence of the crack could be identified; and the third mode seems to be better than first 
mode. Whereas Figure 12(d) gives better results [than Figure 12 (b)] since it can sense the crack presence even from an earlier stage of crack (when crack depth ratio is $>0.2$ ) for both modes.

Figure 13 shows experimental and numerical comparisonfor first and second modes for acceleration, velocity and displacement amplitudes. It can be observed from the amplitude curves of Figure 13 that the amplitude ratios of all the modes increase for the resonant frequencies asthe crack depths ratio increases. The trend of agreement between experimental and numerical values is very good, especially for all the first modes; however only a small change occurs in amplitudes values at all the second modes. Also it can be seen from numerical acceleration results that it gives a much better indication of the crack presence even from the beginning stages of the crack but the sensitivity seems to be much higher for velocity amplitude ratios.

Figure 14 shows the slope of the first and second experimental and numerical modal amplitudes. These figures show that velocity and displacement slopes give a much better indication of the crack presence than the slope of acceleration. It can be observed from Figures 14(b) and (c) that the crack is present even from beginning stages (since the sensitivity at lower crack depths is much higher) while Figure 14(a) shows a definite presence of the crackbeyond a crack depth ratio of 0.2 .

Figures 15 (a) to (c) show the changes that occur in the resonant frequencies (experimental and numerical results) as the crack depth ratio increases from 0.0 to 0.7. Figure 15(a) shows the changes that occur in the non-dimensional frequency ratios $\left(\omega_{\text {cracked }} / \omega_{\text {un-cracked }}\right)$ for the first four vertical bending frequencies as the crack depth ratio increases. It is observed that the changes in non-dimensional frequency ratios are not appreciable for a crack depth ratio less than 0.5 (in this range the non-dimensional frequency ratio is greater than 0.98 ). This crack depth ratio is quite large for crack detection since the structure may tend to fail catastrophically beyond this crack depth. Hence for these types of shafts, we need to obtain another type of measure that could indicate the crack presence much earlier. Figure 15(b) shows the relationships that exist between experimental measurements and numerical computations of non-dimensional frequency ratios for all crack depths (for different modes). At lower crack depth ratios $(<0.4)$ the relationship is almost linear; as crack depth ratio increases beyond this, the relationship tends to become slightly nonlinear. This seems to imply that the nonlinear effect on the resonant frequencies is marginal at crack depth ratios are less than 0.4 ; even beyond this crack depth ratio the nonlinear effect is not significant.

Considering the results presented for amplitude measurement in Figures 11 to 14, it appears that measurements and comparisons made at resonant frequencies seem to be more reliable for both amplitude measurements and its slope than those at anti-resonant frequencies. Moreover sensitivity of prediction seems to be better for slopes of normalizedamplitude vs. crack depth ratio than that for normalized amplitude ratio vs. crack depth ratio [since it could be observed from Figure 12 that change in normalized amplitude ratios vary from 1.0 to 1.5 (for first mode) between a crack depth ratio of 0.0 to 0.4 ; whereas the change in slopes is much higher, varying from 0.0 to 5.0 (for first mode) between a crack depth ratio of 0.2 to 0.5 ]. Also the velocity amplitude comparisons seem to give much better results than the acceleration and displacement amplitude comparisons. In addition the use of results at the second resonant frequency seems to be much superior to that at first frequency.

A better crack detection method is obtained when the slope of the frequency ratio vs. crack depth ratio curve is plotted against the crack depth ratio, as shown in Figure 15 (c). The whole process of determining the slope of the non-dimensional curve vs. crack depth ratio was cast in a mathematical format. First the curves shown in Figure 15(a) were curve-fitted and the algebraic equations that relate very closely the non-dimensional frequency ratio (y) to crack depth ratio $(\mathrm{x}=\mathrm{d} / \mathrm{D})$ was determined for all the four modes. Then these equations were differentiated with respect to crack depth ratio $(=\mathrm{x})$ to obtain the slope equation for the curve.These relationships are indicated in Table 3, given below. From the slope curves shown in Figure 15(c), it can be observed that when the crack depth ratio is greater than 0.2 to 0.25 , one can definitely say that there is a well-defined crack that is present in the structure (for both experimental and numerical results). Thus this gives a better indicator of crack presence in the rotor shaft. Incidentally, the mathematical equations given in Table 3 can also be used to estimate the unknown crack depth ratio, if the different experimental frequency ratios are known for different modes.

Table 4. Mathematical equations obtained for the frequency ratio curve and its slope as a function of crack depth ratio $\left[\mathrm{y}=\left(\omega_{\text {cracked }} / \omega_{\text {un-cracked }}\right) ; \mathrm{x}=(\mathrm{d} / \mathrm{D})\right]$

\begin{tabular}{ccc}
\hline Mode \# & Non-dimensional frequency ratio curve & $\begin{array}{c}\text { Slope of non-dimensional frequency ratio } \\
\text { curve }\end{array}$ \\
\hline Mode 1 & $\mathrm{y}_{1}=-0.519 \mathrm{x} 3+0.330 \mathrm{x} 2-0.070 \mathrm{x}+1.000$ & $\mathrm{dy}_{1} / \mathrm{dx}=-1.557 \mathrm{x}^{\wedge} 2+0.66 \mathrm{x}-0.07$ \\
Mode 2 & $\mathrm{y}_{2}=-0.555 \mathrm{x} 3+0.280 \mathrm{x} 2-0.050 \mathrm{x}+1.000$ & $\mathrm{dy}_{2} / \mathrm{dx}=-1.665 \mathrm{x}^{\wedge} 2+0.56 \mathrm{x}-0.05$ \\
Mode 3 & $\mathrm{y}_{3}=-0.387 \mathrm{x} 3+0.229 \mathrm{x} 2-0.046 \mathrm{x}+1.000$ & $\mathrm{dy}_{3} / \mathrm{dx}=-1.161 \mathrm{x}^{\wedge} 2+0.458 \mathrm{X}-0.046$ \\
Mode 4 & $\mathrm{y}_{4}=-0.656 \mathrm{x} 3+0.371 \mathrm{x} 2-0.070 \mathrm{x}+1.000$ & $\mathrm{dy}_{4} / \mathrm{dx}=-1.968 \mathrm{x}^{\wedge} 2+0.742 \mathrm{x}-0.070$ \\
\hline
\end{tabular}


In a similar manner, the relationships that exist between the non-dimensional anti-resonant frequencies and crack depth ratio are shown in Figure 16(a), (b) and (c). Anti-resonant frequency is the frequency at which the mechanical impedance of the shaft has the largest magnitude (or the mobility has the lowest magnitude). The results are similar to that at resonant frequencies; but the sensitivities seem to be better for anti-resonant frequencies as indicated earlier by (Afolabi, 1987).

Comparing the results shown in Figures 15 and 16 for the change in frequency ratios as a function of crack depth ratios at resonant and anti-resonant frequencies, respectively, sensitivity of measurements seem to be better for the first resonant and first anti-resonant frequencies than that for the higher frequencies. Also uses of slopes of the plots seem to be the most efficient method for detecting the crack presence in the rotating shaft much early. Moreover the use of the results shown in Figure 11 to 16, would give a better procedure in carrying out a first level robust crack measurement and prediction procedure for rotating shafts.
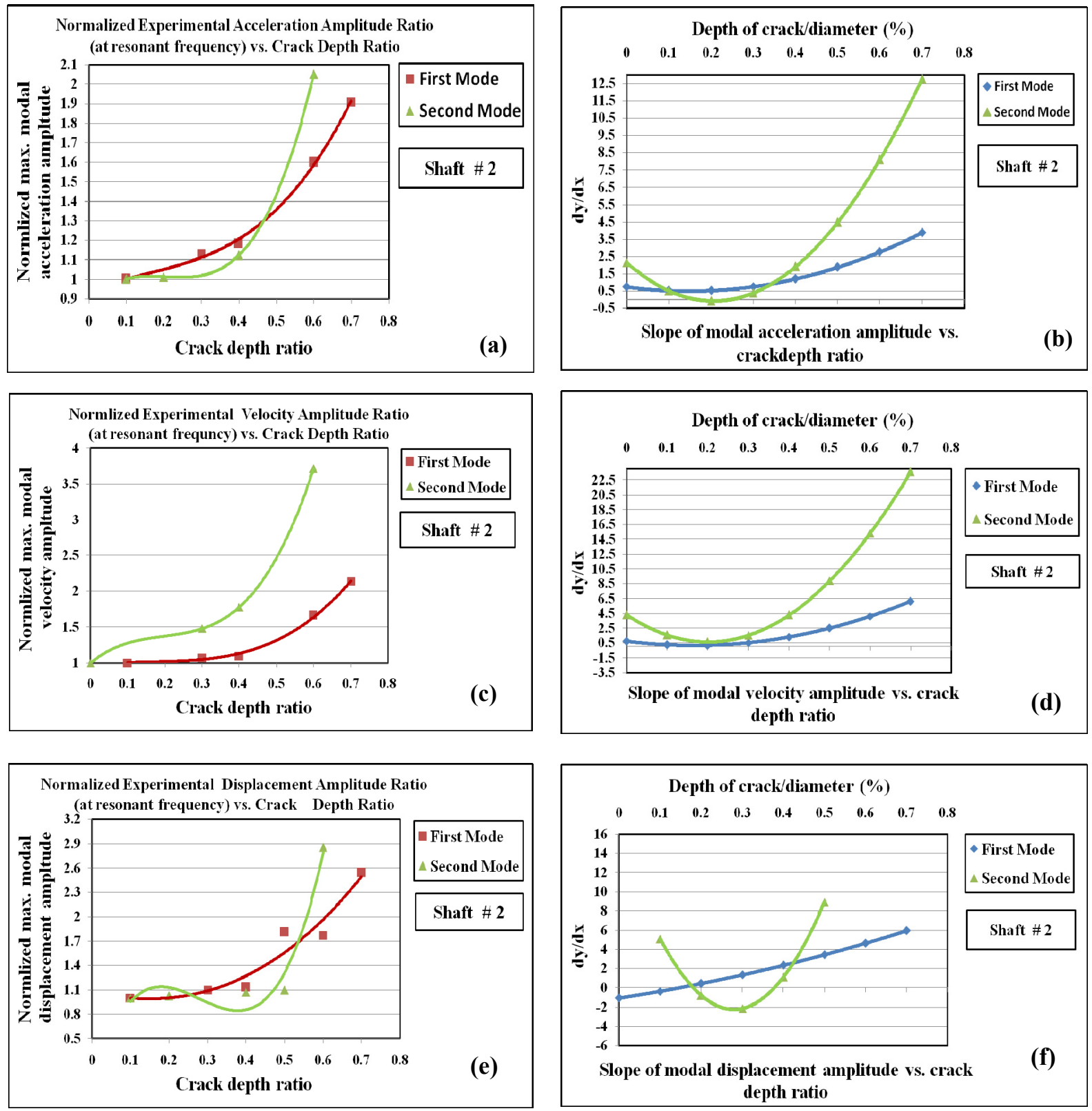

Figure 11. Comparison of experimental results for resonant frequency amplitudes: a) acceleration amplitude versus crack depth ratio; b) slope of modal acceleration amplitude versus crack depth ratio; c) velocity amplitude versus crack depth ratio; d) slope of modal velocity amplitude versus crack depth ratio; e) displacement amplitude versus crack depth ratio; and f) slope of modal displacement amplitude versus crack depth ratio 

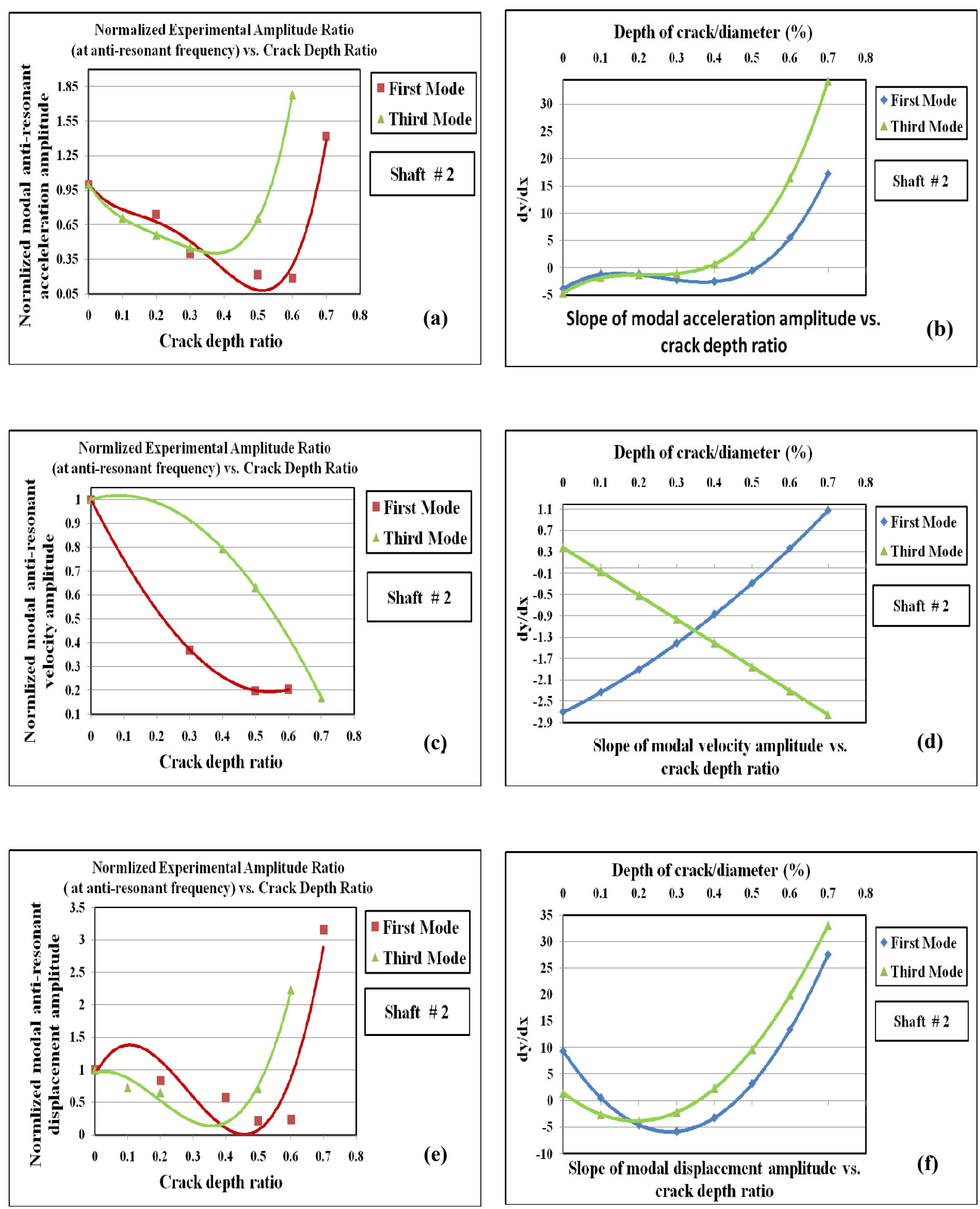

Figure 12. Comparison of experimental results for anti-resonant frequency amplitude response: a) acceleration amplitude versus crack depth ratio; b) slope of modal acceleration amplitude versus crack depth ratio; c) velocity amplitude versus crack depth ratio; d) slope of modal velocity amplitude versus crack depth ratio; e) displacement amplitude versus crack depth ratio; and f) slope of modal displacement amplitude versus crack depth ratio 

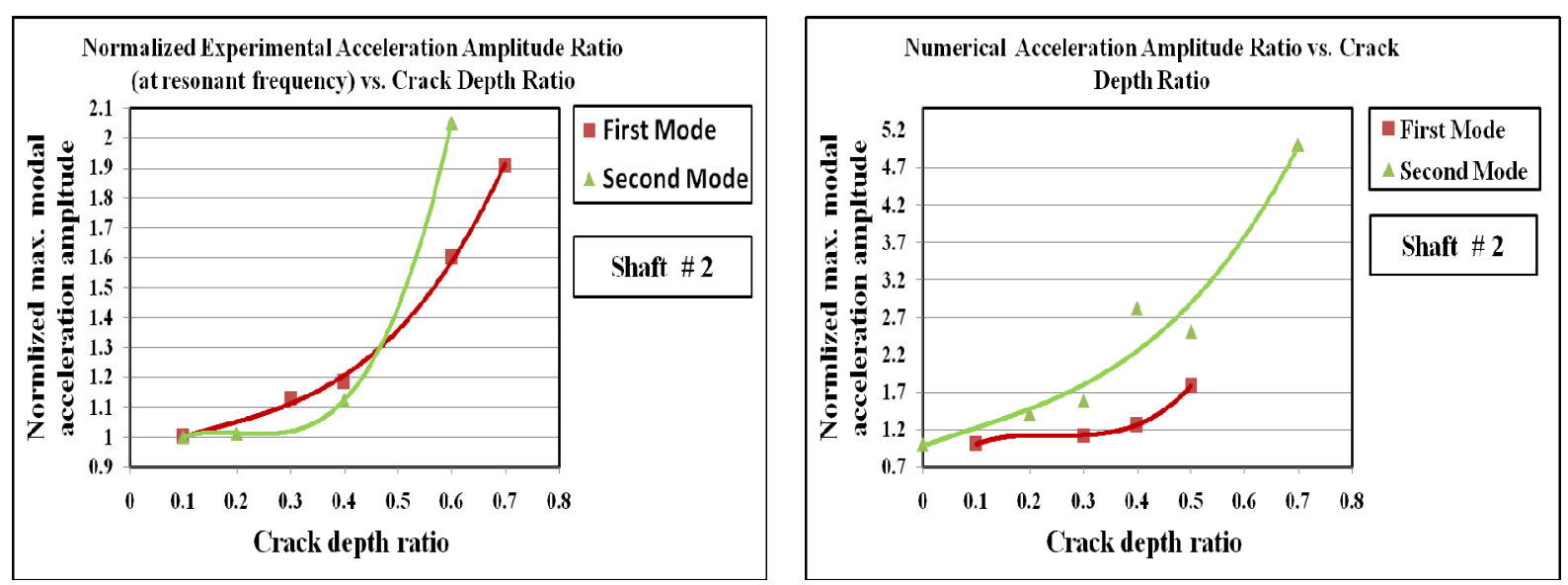

(a)
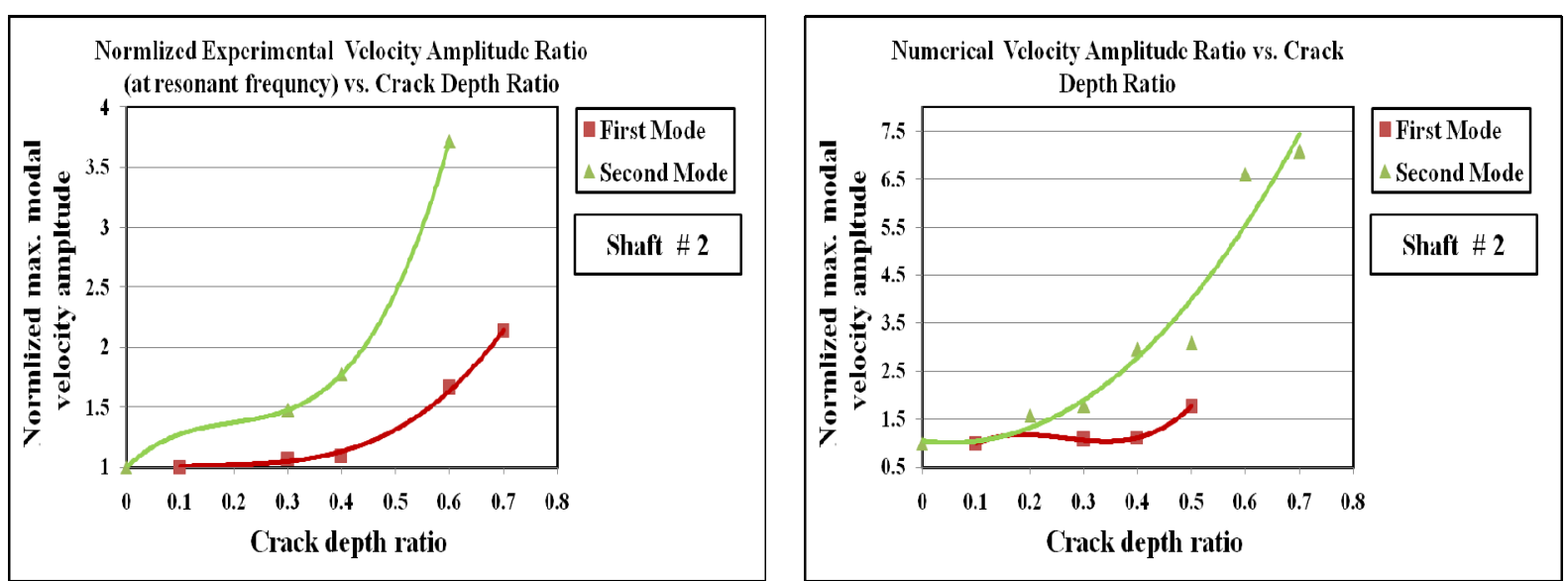

(b)
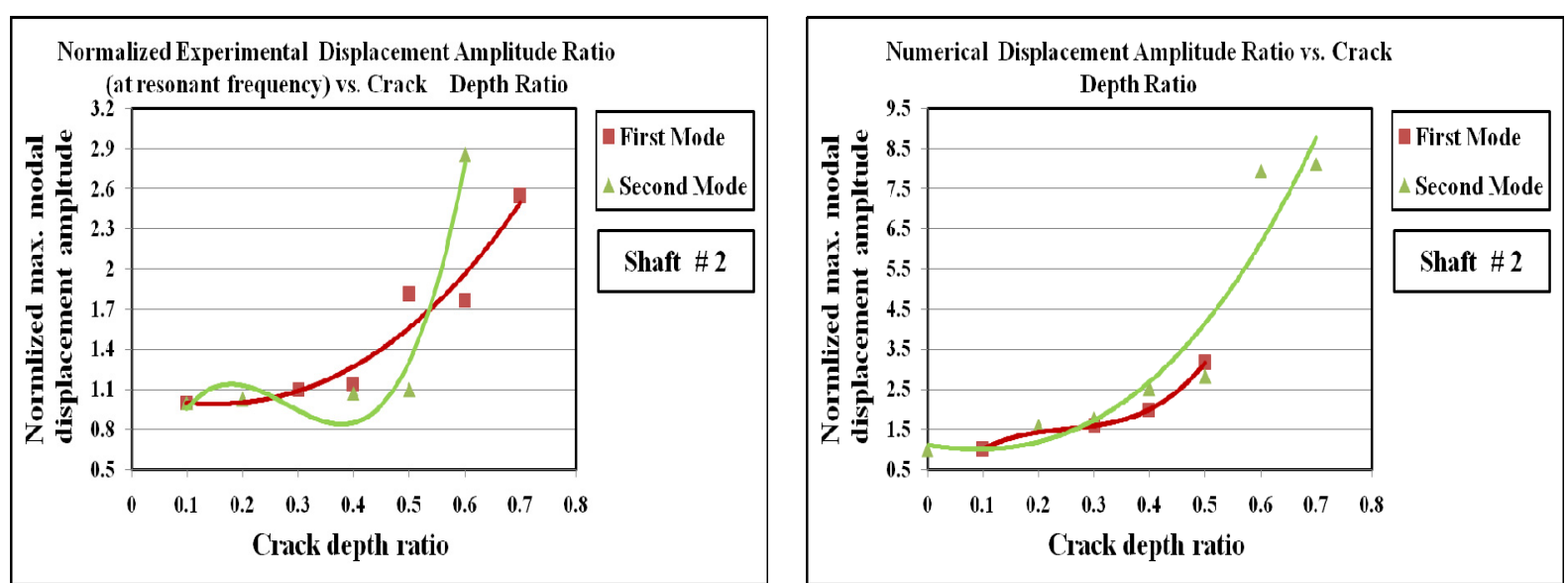

(c)

Figure 13. Comparison of experimental and numerical results for resonant frequency of shaft \# 2 for (first and second modes): a) acceleration amplitude versus crack depth ratio; b) velocity amplitude versus crack depth ratio; and c) displacement amplitude versus crack depth ratio 

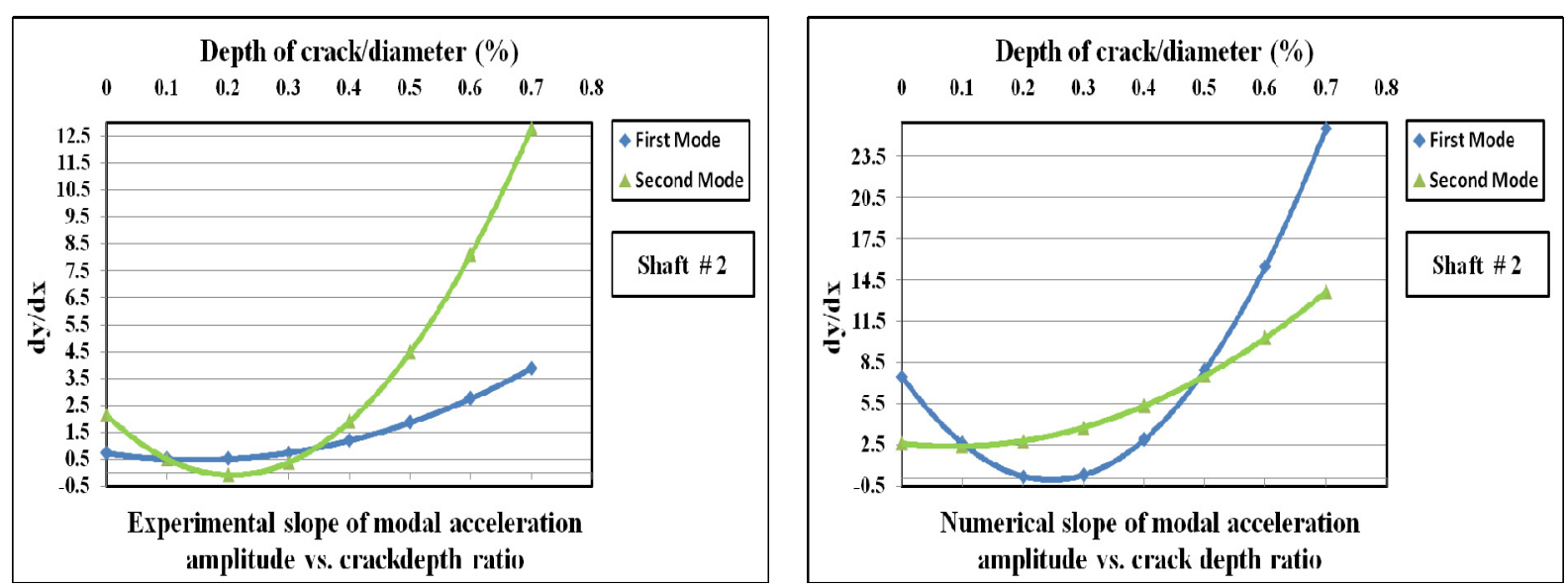

(a)
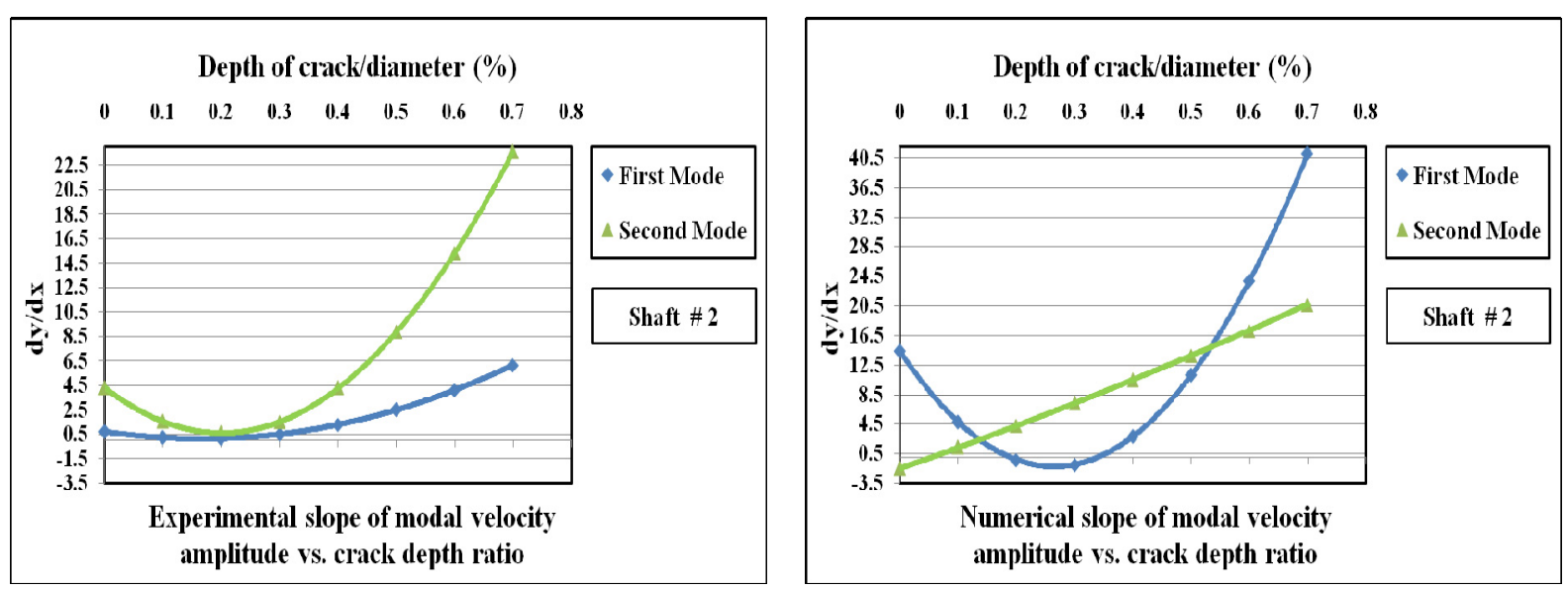

(b)
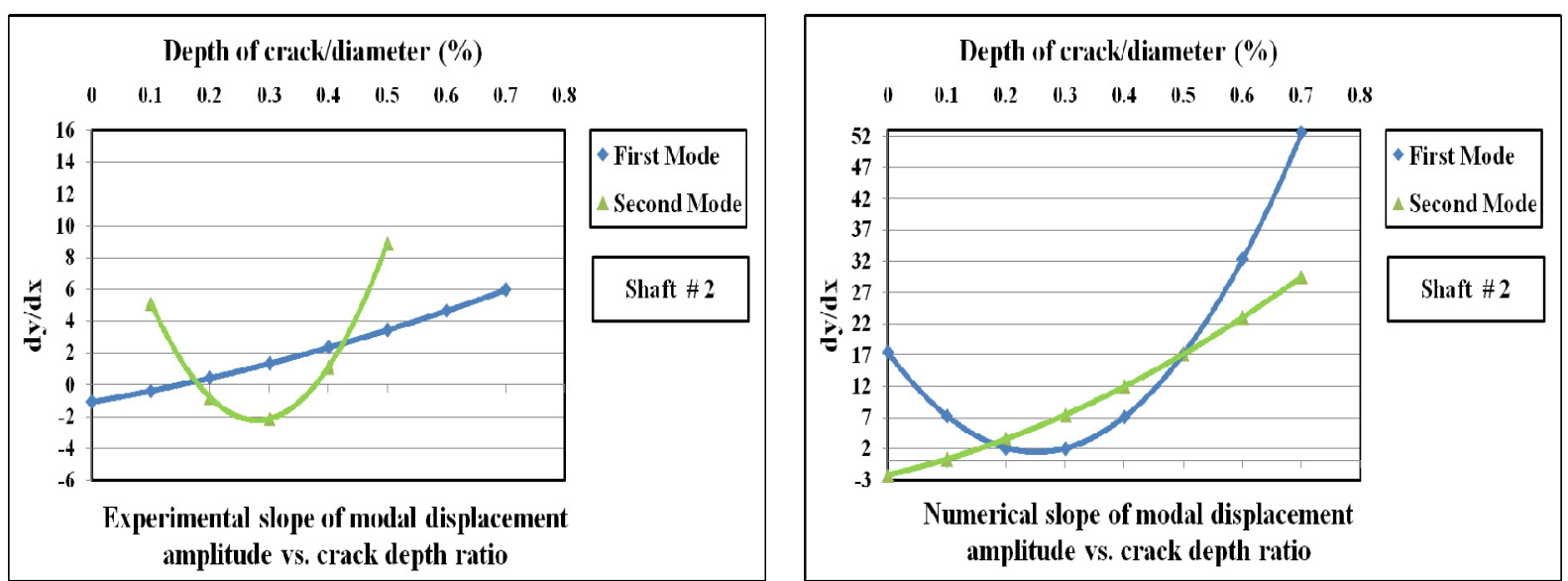

(c)

Figure 14. Comparison of experimental and numerical results for slopes of resonant frequency amplitudes of shaft \# 2 for (first and second modes): a) slope of the modal acceleration amplitude vs. crack depth ratio; b) slope of the modal velocity amplitude vs. crack depth ratio; and c) slope of the modal displacement amplitude vs. crack depth ratio 

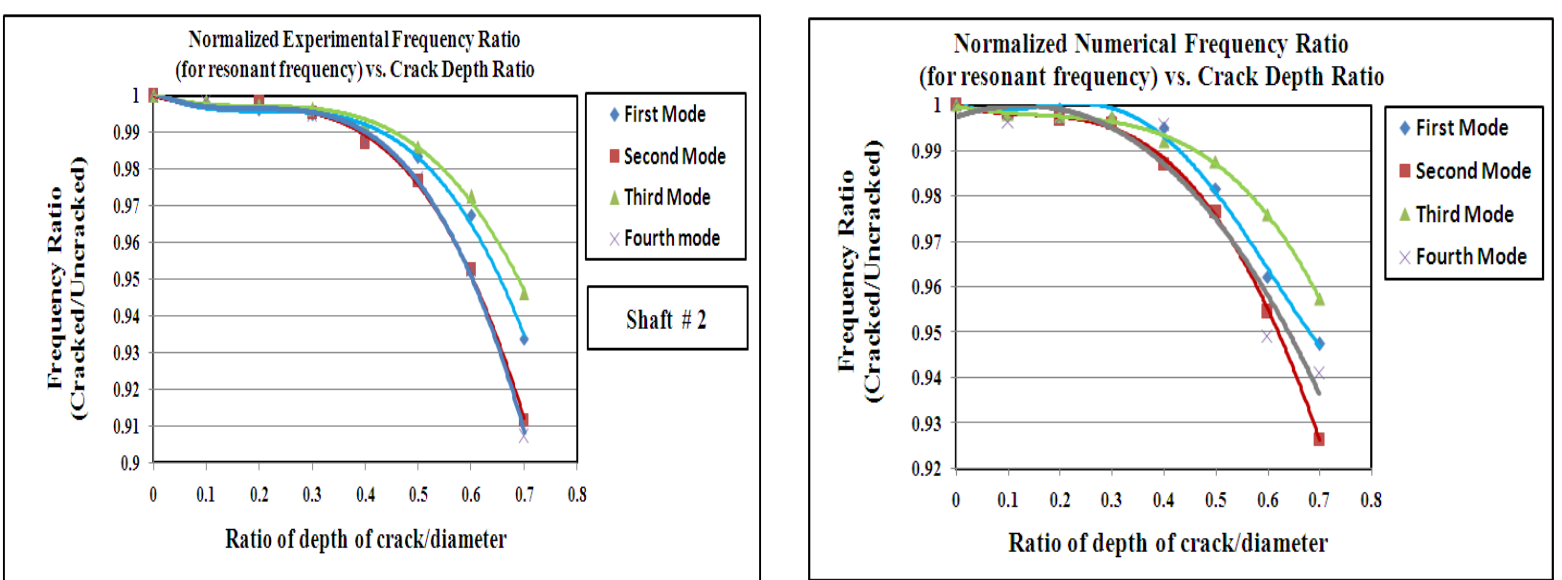

(a)
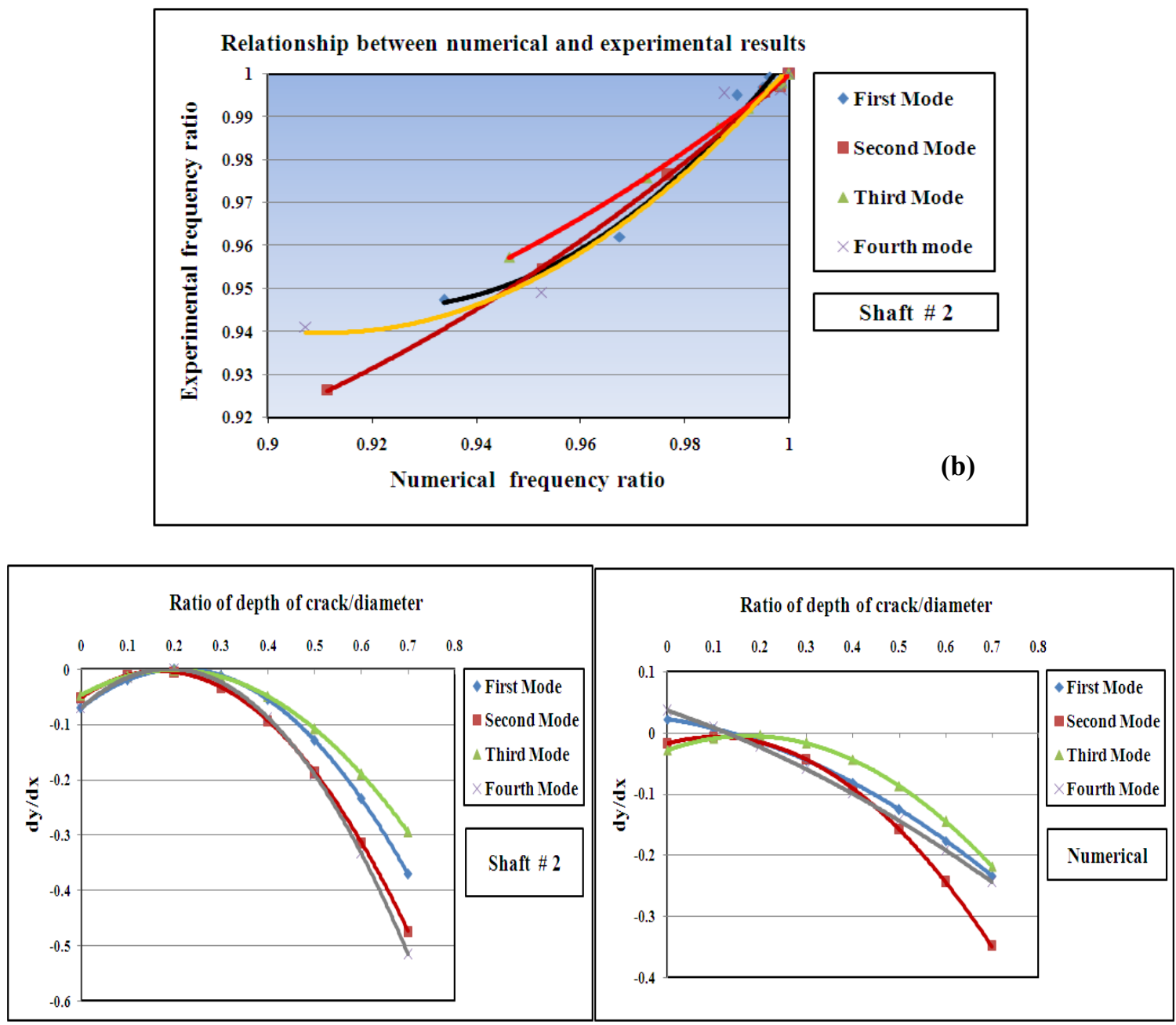

(c)

Figure 15. Comparison of experimental and numerical results of shaft \# 2 for (at four resonant modes): a) experimental and numerical frequency ratio versus crack depth ratio; $b$ ) relationship between numerical and experimental results of frequency ratio; and c) experimental and numerical slope of the frequency ratio vs. crack depth ratio curves 


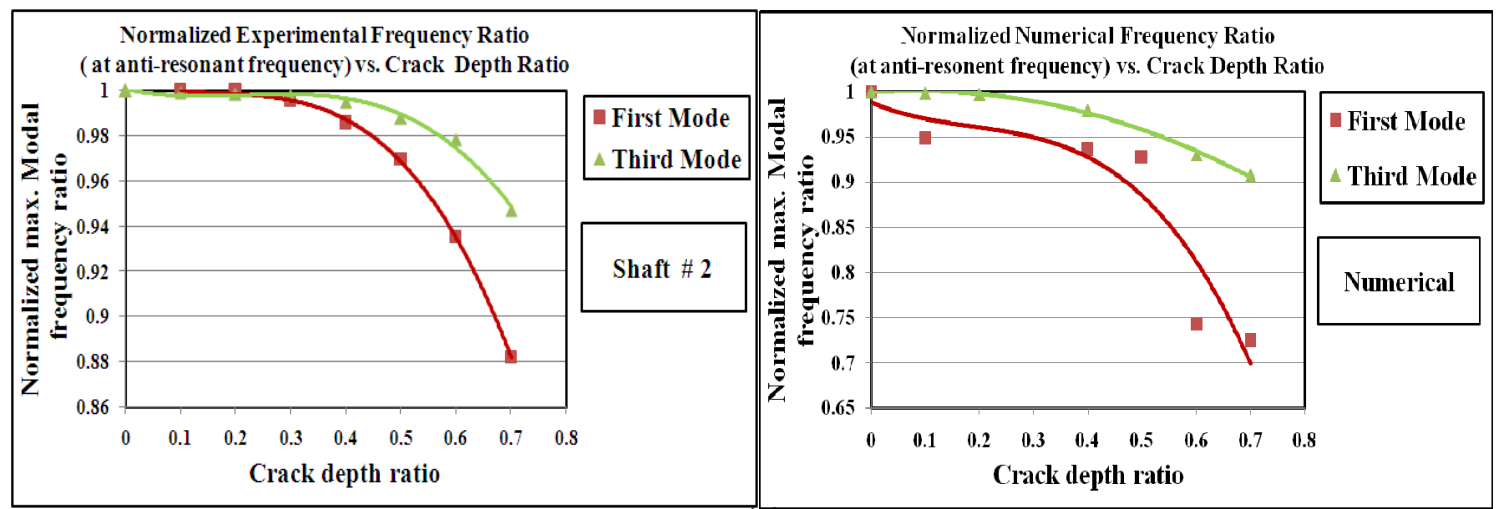

(a)
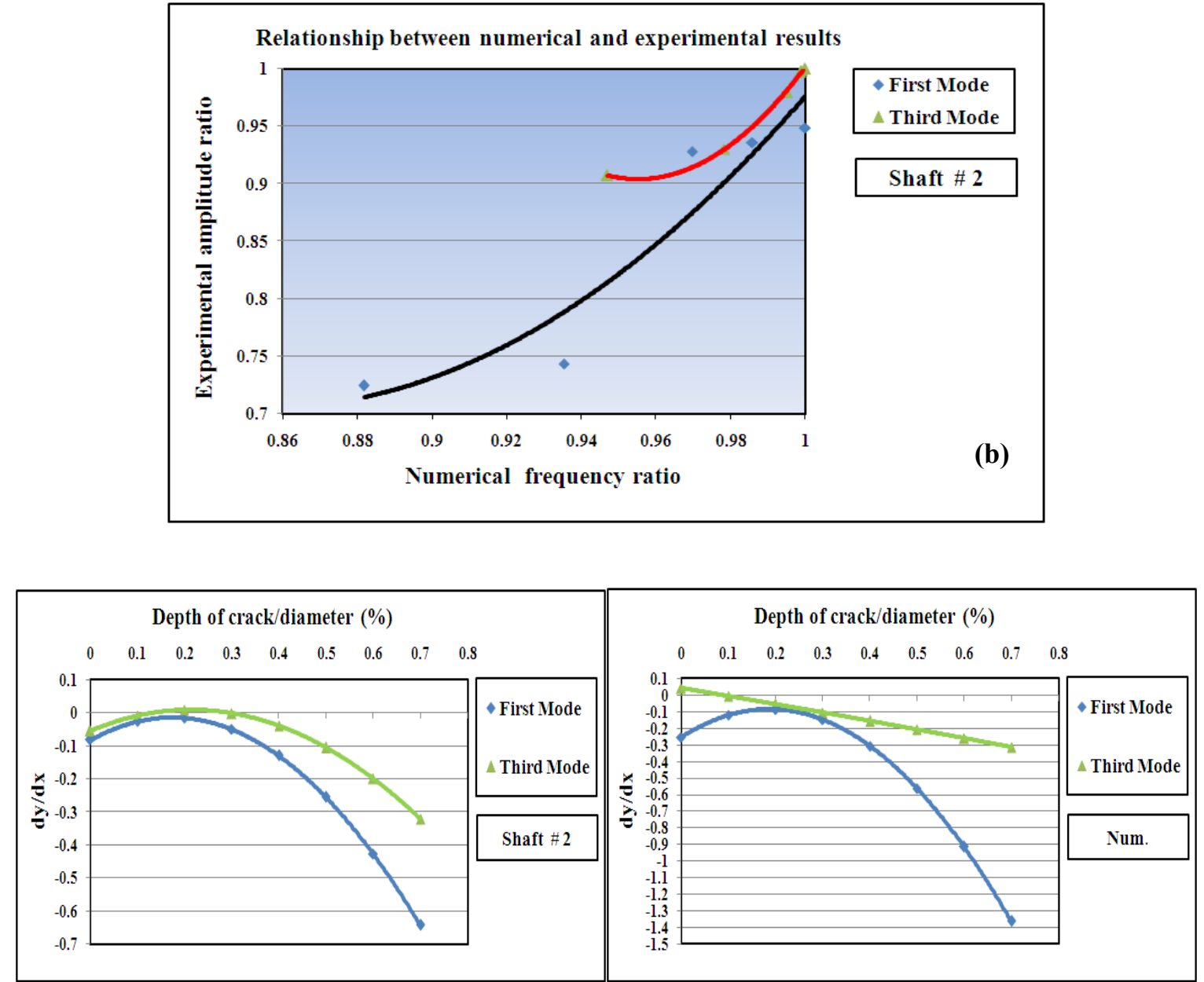

(c)

Figure 16. Comparison of experimental and numerical results for (first and third modal frequencies):

a) experimental and numerical ant-resonant frequency ratio versus crack depth ratio; b) the relationship between numerical and experimental results of anti-resonant frequency ratio and c) experimental and numerical slope of the frequency ratio vs. crack depth ratio

\section{Conclusions}

In this study the propeller-bearing-shaft system has been holistically modeled using FE procedure with the actual in-situ profiles for the propeller, bearings, supports and torque loading aluminum arm. Also vibration analysis for experimental results has been successfullycorrelated with the finite element results. These results show that it is possible to detect the crack presencebeyond the crack depth ratio of $20 \%$. 
The following are some of the conclusions obtained from this study:

(i) When the rates of changes of bending or torsional frequencies are plotted as a function of crack depth ratio, it is possible to detect the presence of crack in a rotating shaft above a crack depth ratio of 0.2 . This will be a very good procedure for detecting the presence of a crack in the rotating shaft.

(ii) The examination of the change of torsional frequencies of a rotating shaft is able to predict the presence of obtained crack even from its beginning stages. This conclusion has to be firmed up by additional experimental and numerical results on a number of shaft configurations.

(iii) The changes that take place in the vibrational amplitudes of the rotating shaft, in terms of its maximum accelerations/velocities/displacements and its slope give a better and more sensitive predictive technique for crack presence when the crack depth ratio is greater than 0.20 .

(iv) It is seen that the monitoring of the rate of changes that occur in the velocity amplitudes (or its inverse impedance amplitudes) would prove to be a better predictive tool in the frequency range considered in this paper.

(v) The curve-fitted equations obtained for the variations of modal frequencies and modal amplitudes, and as well the derivatives of the above equations will give a very good predictive method for the identification of an existing crack in the shaft.

(vi) Also the linearity of results between experimental measurements and numerical predictions indicate that the crack-profile does not become nonlinear tillthe crack depth ratio is greater than 0.40 . Even up to a crack depth ratio of 0.60 (from a crack 0.40 depth ratio) the nonlinearity between experimental measurements and theoretical prediction is not significant.

\section{Acknowledgements}

The authors would like to express their sincere gratitude the staff of the Structural Lab of the Faculty of Engineering and Applied Science at the Memorial University.

\section{References}

Afolabi, D. (1987). An anti-resonance technique for detecting structural damage. Proceedings of Fifth International Model Analysis Conference. London, 1, 491-495.

Citarella, R., \& Cricri, G. (2010). Comparison of DBEM and FEM crack path predictions in a notched shaft $\begin{array}{lllll}\text { under torsion. Engineering } & \text { Fracture }\end{array}$ http://dx.doi.org/10.1016/j.engfracmech.2010.03.012.

Downer, L. (2010). Detecting damage in beams and structures through modal analysis. Master of Engineering thesis, Memorial University, St. John's, NL.

Elshafey, A., Marzouk, H., \& Haddara, M. (2011). Experimental damage identification using modified mode shape difference. Journal of Marine Science, 10, 1-3. http://dx.doi.org/10.1007/s11804-009-7078-4

Ganeriwala, S., Kanakasabai, V., \& Richardson, M. (2011). Modes indicate cracks in wind turbine blades, Presented at IMAC XXIX, Jacksonville, FL. Retrieved from http://www.vibetech.com/assets/papers/paper55.pdf

Hamidi, L. Piaud, J., \& Massoud, M. (1992). A study of crack influence on the modal characteristics of rotors. International Conference on Vibrations in Rotating Machinery, held at Bath, UK, Paper C432/066, 283288.

Huei, L. (2011). Finite element simulations with ANSYS workbench 13 theory - applications - case studies. USA: Stephen Schroff, 34-35. Retrieved from www.SDCpublications.com

Li, X., Yao, H., Ren, Z., \& Wen, B. (2008). Simulation of dynamic characteristics of faulty multi-span rotor system through FEA. 15th International Congress on Sound and Vibration, Daejeon, Korea. http://dx.doi.org/CNKI:SUN:DBDX.0.2008-02-025

Liao, J. B., Zhou, H. F., \& Sun, D. (2012). Research for the crack dynamic monitoring of crank shaft of marine diesel engine based on magnetic memory technology. Information Technology Journal, 11(4), 516-519. http://dx.doi.org/10.3923/itj.2012.516.519

McMaster-Carr. (2011). (Princeton, New Jersey, USA) supplies products (including bearings) used to maintainmanufacturing plants and large commercial facilities worldwide. Retrived on September 15, 2011, from www.mcmaster.com 
Sabnavis, G., Gordon, R., Kasarda, M., \& Quinn, D. (2004). Cracked shaft detection and diagnostics: a literature review. The Shock and Vibration Digest, 36(4), 287-296. Retrieved from http://citeseerx.ist.psu.edu/viewdoc/summary?doi=10.1.1.110.9106

Saravanan, K., \& Sekhar, A. (2012). Crackdetection in a rotor by operational deflection shape and kurtosis using laser vibrometer measurements. Journal of Vibration and Control. http://dx.doi.org/10.1177/1077546312444770

Schwarz, B., \& Richardson, M. (1999). Experimental modal analysis. Jamestown, California: Vibrant Technology, Inc. 95327.

Sekhar, A., \& Srinivas, B. (2003). Dynamics of cracked composite shafts. Journal of Reinforced Plastics and Composites, 22(7), 637-653. http://jrp.sagepub.com/content/22/7/637

Sinou J. J., \& Lees, A. W. (2007). A Non-linear study of a cracked rotor. European Journal of Mechanics and Solids, 26, 152-170. Retrieved from http://www.sciencedirect.com/science/journal/09977538

Sudhakar, G., \& Sekhar, A. (2010). Model based shaft crack identification in rotating machinery. Turbine Technical Conference and Exposition presented by ASME International Gas Turbine Institute, 6(23812), 473-480. http://dx.doi.org/10.1115/GT2010-23812

Tlaisi, A., Swamidas, A. S. J., Haddara, M. R., \& Akinturk, A. (2011). Modeling and calibration for crack detection in circular shafts supported on bearings using lateral and torsional vibration measurements. Advances in Mechanical Engineering. (Accepted for publication). http://dx.doi.org/10.1155/2012/519471

Zakhezin, A., \& Malysheva, T. (2001). Modal analysis rotor system for diagnostic of the fatigue crack. Condition Monitoring Conference, St. Catherine's College, Oxford, UK. 